\title{
Rapid dispersal of a hydrothermal plume by turbulent mixing
}

\author{
Maren Walter,a , Christian Mertens ${ }^{\mathrm{a}}$, Uwe Stöber ${ }^{\mathrm{a}}$, Christopher \\ R. German ${ }^{\mathrm{b}}$, Dana R. Yoerger ${ }^{\mathrm{b}}$, Jürgen Sültenfuß ${ }^{\mathrm{a}}$, Monika Rhein ${ }^{\mathrm{a}}$, Bernd \\ Melchert $^{\mathrm{c}}$, Edward T. Baker ${ }^{\mathrm{d}}$ \\ ${ }^{a}$ Institut für Umweltphysik, University of Bremen, PB 330440, 28334 Bremen, Germany \\ ${ }^{b}$ Woods Hole Oceanographic Institution, 266 Woods Hole Road, Woods Hole, MA 02543, \\ $U S A$ \\ ${ }^{c}$ Leibniz-Institute of Marine Sciences IfM-GEOMAR, Wischhofstr. 1-3, 24148 Kiel, \\ Germany \\ ${ }^{d}$ Pacific Marine Environmental Laboratory, NOAA, 7600 Sand Point Way NE, Seattle, \\ WA 98115-6349, USA
}

\begin{abstract}
The water column imprint of the hydrothermal plume observed at the $\mathrm{Ni}$ belungen field ( $8^{\circ} 18^{\prime} \mathrm{S} 13^{\circ} 30^{\prime} \mathrm{W}$ ) is highly variable in space and time. The off-axis location of the site, along the southern boundary of a non-transform ridge offset at the joint between two segments of the southern Mid-Atlantic Ridge, is characterized by complex, rugged topography, and thus favorable for the generation of internal tides, subsequent internal wave breaking, and associated vertical mixing in the water column. We have used towed transects and vertical profiles of stratification, turbidity, and direct current measurements to investigate the strength of turbulent mixing in the vicinity of the vent site and the adjacent rift valley, and its temporal and spatial variability in relation to the plume dispersal. Turbulent diffusivities $K_{\rho}$ were
\end{abstract}

\footnotetext{
*Corresponding author

Email address: mwalter@physik.uni.bremen.de (Maren Walter)
} 
calculated from temperature inversions via Thorpe scales. Heightened mixing (compared to open ocean values) was observed in the whole rift valley within an order of $K_{\rho}$ around $10^{-3} \mathrm{~m}^{2} \mathrm{~s}^{-1}$. The mixing close to the vent site was even more elevated, with an average of $K_{\rho}=4 \times 10^{-2} \mathrm{~m}^{2} \mathrm{~s}^{-1}$. The mixing, as well as the flow field, exhibited a strong tidal cycle, with strong currents and mixing at the non-buoyant plume level during ebb flow. Periods of strong mixing were associated with increased internal wave activity and frequent occurrence of turbulent overturns. Additional effects of mixing on plume dispersal include bifurcation of the particle plume, likely as a result of the interplay between the modulated mixing strength and current speed, as well as high frequency internal waves in the effluent plume layer, possibly triggered by the buoyant plume via nonlinear interaction with the elevated background turbulence or penetrative convection.

Key words: physical oceanography, hydrothermal vents, diapycnal mixing, plume dispersal, Mid-Atlantic Ridge, rift valleys 


\section{Introduction}

Hydrothermal systems act as a bridge from the earths' mantle to the ocean, cooling the mantle by supplying heat from the earths interior to the deep ocean, transferring chemical species like metals or gases from the crust to the water column, and, by allocating energy in form of sulfur, methane or hydrogen molecules, they sustain oases of life for a variety of deep-sea chemosynthetic life forms from bacteria to mussels and shrimps. The export of matter from hydrothermal systems into the ocean takes place in form of the plume, a trail of hydrothermal products carried by a mixture of hydrothermal fluids and ambient sea water (e.g. Lupton, 1995).

The rising height of a plume is determined by the density contrast between this admixture and the surrounding water, which is controlled mainly by the heat output of the vent and the rate of entrainment of ambient water (e.g. Turner and Campbell, 1987). The further dispersal of the plume is controlled by mixing and the ocean currents (Speer et al., 2003): on slow spreading ridges, with their deep axial valleys, the currents and thus the path of a plume originating in the rift valley are controlled and steered by the bathymetry (e.g. German et al., 1998). Depending on the geometry of the valley, inertial and/or tidal currents may be superimposed on the background flow or even dominant (e.g. Thomson et al., 1990; Cannon et al., 1991; Rudnicki et al., 1994; Thomson et al., 2003; Thurnherr and Speer, 2003; Garcia Berdeal et al., 2006). For example, Mihály et al. (1998) found indications for nonlinear interaction between inertial and tidal oscillations in moored current timeseries from the Juan de Fuca Ridge (CoAxial and Endeavour segments). At exposed off-axis locations, complex current structures will de- 
velop: the background flow may be modified by vertical motions, waves and tides (Thurnherr and Richards, 2001; Thurnherr et al., 2002). The plume dispersal in this case is much more affected by small scale oceanic processes like internal waves and diapycnal mixing than in the case of a steady background flow.

The newly discovered Nibelungen hydrothermal vent field in the South Atlantic, located on the slow spreading Mid-Atlantic Ridge (MAR) between the Ascension and Bode Verde Fracture Zones (Fig. 1a), is such an exposed site. The field is mainly extinct, with only one known active hot smoker, the "Drachenschlund" ("Dragon Throat") that is surrounded by several inactive chimney structures (Fig. 2). Nibelungen is an off-axis ultramafic-hosted system, located south of a non-transform offset between two adjacent 2ndorder ridge-segments (Melchert et al., 2008), an area named "Cheating Bay" because of the transient and deceiving nature of the water column plume (Keir et al., 2008). The setting is characterized by rugged topography with lots of scarps, fault blocks and topographic steps (Fig. 1b,c). The smoker Drachenschlund has not a typical chimney structure, but is a smoking hole of approximately $0.5 \mathrm{~m}$ diameter, situated at the bottom of a $4 \mathrm{~m}$ deep and $6 \mathrm{~m}$ wide crater at the eastern scarp of a fault block, approximately $80 \mathrm{~m}$ below the crest (Melchert et al., 2008).

The hydrothermal plume of the Nibelungen field was first discovered and sampled in 2004 during the Meteor cruise M62/5. After initial surveying of the Mid-Atlantic Ridge segments south of the Ascension Fracture Zone with a towed sidescan sonar and turbidity sensors, the Cheating Bay area was identified as a likely location for hydrothermal activity based on turbidity 
and methane anomalies in the water column (Devey et al., 2005). The actual site of the Drachenschlund was discovered in 2006 during cruise M68/1 in a water depth of $2915 \mathrm{~m}$ at $8^{\circ} 17.87^{\prime} \mathrm{S}, 13^{\circ} 30.45^{\prime} \mathrm{W}$ by $A B E$, an autonomous underwater vehicle (German et al., 2008), and the german ROV Quest (Koschinsky et al., 2006).

The discovery of the source was delayed by the variability of the plume; the largest anomalies were repeatedly observed about half a mile southwest of the Drachenschlund, but these observations were interspersed with a recession to background values (e.g., less $\mathrm{CH}_{4}$ or turbidity than the far-field signal in the axial valley), and linked to a seemingly erratic flow field.

In this work, we investigate the influence of turbulent diapycnal mixing, that varies considerably with local bathymetry and tidal phase, on the dispersal of the Drachenschlund plume.

\section{Measurements}

Hydrographic measurements were obtained during two cruises (M62/5 and M68/1) of Meteor in November/December 2004 and April/May 2006. On the first cruise 32 CTD casts were carried out in the region (covering about $15 \times 20 \mathrm{~km}$ ), which were intended to map the helium, methane and turbidity distribution of the Nibelungen hydrothermal plume (Fig. 1c). Additionally three towed yoyo casts were made for closer location of the source, an attempt that was hampered by the large hydrographic variability in the area. During the second cruise the CTD station with the highest methane concentration from cruise M62/5 was repeated and two additional tow-yo tracks (Fig. 1b) were made (a complete list of stations is available online as 
part of the supplementary material to Keir et al., 2008).

CTD measurements and water sampling have been carried out with an SBE 32 carousel water sampler which carried an SBE 9plus underwater unit. After calibration, the accuracy of the CTD sensor data was $0.001 \mathrm{~K}$ for temperature and $0.002-0.003$ for salinity. Additional hydrographic and turbidity data were obtained using miniature autonomous plume recorders (MAPR, Baker and Milburn, 1997). MAPRs are self-contained instruments, that record data at pre-set time intervals from temperature, pressure, and nephelometer (SeaPoint Sensors, Inc. Backscatter Sensor, LBSS) sensors; units of backscatter are given as $\Delta \mathrm{NTU}$, nephelometric turbidity units above ambient sea water. During M62/5 the CTD was equipped with a supplementary WET Labs C-Star transmissometer, but comparison to the MAPR backscatter showed that the instrument was periodically malfunctioning (possibly caused by connector problems); during M68/1 the real-time CTD turbidity measurements were carried out with a backscatter sensor similar to the one on the MAPRs. ABE was equipped with two SeaBird sensors, an SBE3 and an SBE4, and SeaPoint optical backscatter sensor for plume mapping; current direction and magnitude were inferred from bottom and water lock velocities from the acoustic Doppler velocity log (German et al., 2008).

The water sampling concentrated on helium and methane: the methane was analyzed on board as a tool for plume detection (see Keir et al., 2008), while water samples for helium isotopes analysis were collected on both cruises using pinched-off copper tubes for later analysis in the lab. Ashore the dissolved gases were separated from the water in a high vacuum system and stored in glass ampoules. For the analysis, the ampoules were cut off, 
and helium as well as neon were separated from other gases in cryo-traps at $25 \mathrm{~K}$ and $14 \mathrm{~K}$. He isotopes were analyzed with a high resolution static mass spectrometer (MAP 215-50). The system is capable to resolve ${ }^{3} \mathrm{He}$ from the mass-3 hydrogen species (HD and $\mathrm{H}_{3}$ ) leaking from metal walls. The high stability of the system provides an uncertainty of $<0.5 \%$ for ${ }^{3} \mathrm{He} /{ }^{4} \mathrm{He}$ ratio (Sültenfuss et al., 2008).

Two RDI $300 \mathrm{kHz}$ Workhorse Monitor ADCPs mounted on the water sampling unit were used for full-depth current profile measurements during the cast on both cruises. The LADCP raw data have been processed with an inverse method as described by Visbeck (2002) using the barotropic, bottom track and smoothness constraints. The bin length, i.e. the vertical resolution, was set to $10 \mathrm{~m}$, which results an accuracy of $2 \mathrm{~cm} \mathrm{~s}^{-1}$.

\section{The Nibelungen Plume}

The mapping of the Drachenschlund plume (and the discovery of the vent site) was hampered by the high degree of temporal and spatial variability, both in the background hydrography and in the plume signal itself. During the first survey in 2004, maximum $\mathrm{CH}_{4}$ concentrations of $120 \mathrm{nmol} \mathrm{L} \mathrm{L}^{-1}$, $600 \mathrm{~m}$ to the southwest of the smoker, were the strongest indicator of a close hydrothermal vent site in the watercolumn (Keir et al., 2008); they were accompanied by a peak in turbidity between 2550 and $2750 \mathrm{~m}$ depth (Fig. 3). In general, the highest concentrations of hydrothermal material in the effluent layer were found at this site, coinciding with the predominant southwestward flow direction in the plume layer and below during ebb tide (Keir et al., 2008). The station was reoccupied four times (once during the 
first survey, 10 days later; three times in 2006, including the tow-yos). Of the five realizations, three had strong plume signals, while the other two not only showed no strong plume signal, but merely had background strength in the chemical parameters, less than the far-field plume in the axial valley (Keir et al., 2008), and only a weak turbidity anomaly.

The strong methane and turbidity signals were not unambiguously linked to temperature and salinity anomalies. In principle, since the salinity in the Atlantic Ocean below 1500 m decreases with depth, the injection of hot water at the seafloor should produce an effluent layer which is colder and less saline than the surrounding water (Speer and Rona, 1989). In Cheating Bay, the exposed nature of the vent location leads to a high variability in the flow field that results in a large scatter in temperature and salinity. Thus, the anomalies of about $-0.008{ }^{\circ} \mathrm{C}$ in temperature and -0.002 in salinity of the particle plume are effectively masked: While they can be identified in conjunction with the turbidity signal in the red curve in Fig. 3b, they lie well within the range of the background scatter of temperature and salinity.

In 2006, an ABE survey (Fig. 4), as well as five towed CTD casts with attached MAPRs (Fig. 5, cf. Fig. 1b) have been carried out to map out the hydrothermal plume in the vicinity of the source. All of the mapping was conducted prior to the discovery of the vent site, with the aim of narrowing down the area of its possible location. A typical tow-yo cast lasted approximately 3 hours in the plume range, during which the ship drifted with a speed between 0.5 and 1 knots, and the instrument package was profiling between $2500 \mathrm{~m}$ and the seafloor. The ABE track covers most of the Cheating Bay area with a rectangle of approximately $2.5 \times 3 \mathrm{~km}$ extent, the subsequently 
discovered Drachenschlund located in the northeast corner. The vehicle was pre-programmed to fly a pattern at a fixed depth with ca. $300 \mathrm{~m}$ spacing to map out the non-buoyant plume (Phase 1 survey, see German et al., 2008, for details). The survey depth of $2700 \mathrm{~m}$ was chosen based on the depth range of the particle plume observations during the M62/5 CTD station work.

The presence of the plume is indicated by turbidity anomalies of varying strength, which were found during all five tow-yo casts as well as during the ABE mission. At the $2700 \mathrm{~m}$ depth horizon, the ABE mapped the core of the non-buoyant plume signal approximately $400 \mathrm{~m}$ to the west of the vent site; a more diluted, weak signal is found farther away to the southwest. Although the vehicle flew directly over the vent during the start of the survey (Fig. 4), there was almost no turbidity signal visible at non-buoyant plume height, directly above the vent-location.

During the tow-yos, elevated turbidity values of up to $0.015 \Delta \mathrm{NTU}$ were found at the beginning of the westernmost tow (1287, cf. Fig. 1b, Fig. 5a), to the west of Drachenschlund. The plume signal occupied a temperature range from $2.40^{\circ} \mathrm{C}$ to $2.52^{\circ} \mathrm{C}$, with the maximum found at $2.48^{\circ} \mathrm{C}$, and occasional isolated signals below the $2.4^{\circ} \mathrm{C}$ isotherm. On the southernmost track (1265, cf. Fig $5 b$ ), where the entire cast was south of the vent, turbidity was only slightly elevated as compared to background, and only in the lower core of the plume, at temperatures ranging from $2.36^{\circ} \mathrm{C}$ to $2.45^{\circ} \mathrm{C}$. Tracks 1257 and 120 (cf. Fig 5c,d) both proceed close to the Drachenschlund, but capture very different plume signals. The former shows a very homogeneous, if relatively weak, turbidity signal between $2.38^{\circ} \mathrm{C}$ and $2.48^{\circ} \mathrm{C}$ from the onset of the tow, very close to the source, propagating along track to the northwest. The lat- 
ter, on the other hand, shows the strongest turbidity signal of all tows, with a maximum turbidity around $0.1 \Delta \mathrm{NTU}$ at a temperature of $2.55^{\circ} \mathrm{C}$. This maximum occurs towards the end of the tow, to the east of the Drachenschlund (Fig. 6), while during the first two thirds of the record, west of the vent, only diffuse plume signals colder than $2.50^{\circ} \mathrm{C}$ were observed. Track 103 (cf. Fig 5e) is located parallel to 1287, but upslope, closer to the Drachenschlund. The distribution of the plume signal is very similar, with a shallow maximum in turbidity, centered around $2.53^{\circ} \mathrm{C}$ due west of the vent site. The lower boundary of the plume is given by the $2.44^{\circ} \mathrm{C}$ isotherm, and stretches farther south than the maximum; the deeper part is completely missing. From these observations, the particle plume is sheared in the vertical; the lower part is weaker and spreads in a general south/southwest direction, while the maximum in the effluent layer is transported toward the west.

Farther away from the vent site in the axial valley, the plume signal is weaker, but more uniform; traces of turbidity, methane and helium anomalies are found up to distances of $12 \mathrm{~km}$ away from the source in cross- and alongvalley directions (cf. Devey et al., 2005; Keir et al., 2008). Emitted mantle helium at mid-ocean ridges has an approximately 8 -fold higher ${ }^{3} \mathrm{He} /{ }^{4} \mathrm{He}$ ratio than the atmosphere. The excess $\delta^{3} \mathrm{He}$ (relative difference of ${ }^{3} \mathrm{He} /{ }^{4} \mathrm{He}$ ratio from atmospheric air in \%) is thus an excellent tracer of hydrothermal fluids, which is not vulnerable to chemical reactions or modification by biomass interaction, but only diluted by mixing with ambient water. The rapid return to background values away from the vent site can be seen on the transect of the $\delta^{3} \mathrm{He}$ signal of the Drachenschlund across Cheating Bay (Fig. 7): the measured maxima of $10 \%$ in the lower core and $7 \%$ in the upper core water 
column on this transect (casts 1230 and 1239, resp.) fall back to a background of $4 \%$ at about $4 \mathrm{~km}$ away from the smoker. The background above the southern MAR is the already elevated compared to open ocean (e.g. JeanBaptiste et al., 2008; Keir et al., 2008) because of the hydrothermal activity along the ridge, which can be traced several 100s of kilometers away from the ridge at mid-depths (e.g. Rüth et al., 2000). Interestingly, $\delta^{3} \mathrm{He}$ drops back faster to rift valley background than $\mathrm{CH}_{4}$, possibly indicative of more basaltic than ultramafic fluid sources on a segment scale.

The most prominent property of the non-buoyant plume is a bifurcation into two maxima (e.g. Ernst et al., 2000): an upper one (generally stronger in methane and turbidity) bounded by the density surfaces $\sigma_{3}=41.45$ and $41.46 \mathrm{~kg} \mathrm{~m}^{-3}$ and a secondary maximum below, between the isopycnals $\sigma_{3}=41.46$ and $41.47 \mathrm{~kg} \mathrm{~m}^{-3}$ (Fig. 7). The upper and lower isopycnals correspond to potential temperatures of about $2.55^{\circ} \mathrm{C}$ and $2.4^{\circ} \mathrm{C}$, respectively, and a plume depth range roughly between $2600 \mathrm{~m}$ and $2900 \mathrm{~m}$, depending on the location (cf. Fig. 3). The shallowest part of the plume in the vicinity of the source equals a maximum rising height of the plume of $290 \mathrm{~m}$, corresponding to a thermal output of $(60 \pm 15) \mathrm{MW}$ and a volume flux of $(40 \pm 10) \mathrm{L} \mathrm{s}^{-1}$ (Melchert et al., 2008).

\section{Flow Field and Tides}

\subsection{Analysis of tidal phase}

The tidal state of the individual current measurements was determined from the barotropic TPXO tidal model, which is based on inverse modeling of TOPEX/Poseidon altimeter data (Egbert and Erofeeva, 2002). The ap- 
plicability of the model has been tested by comparison between measured barotropic velocity fluctuations and the corresponding model prediction. To produce the time series of observations required for such a comparison, data from all Lowered ADCP profiles (44 profiles, tow-yo stations not included) in the area (cf. Fig. 1c) were pulled together and treated as if they were recorded at the same position. This assumption is warranted by the resolution of the TPXO tidal model that does not resolve the spatial variability in the survey area. To determine amplitude and phase of the tidal components, a complex demodulation (harmonic analysis in the complex plane) of the measured velocities has been carried out in two layers: an upper layer in the non-buoyant plume density range $41.44 \mathrm{~kg} \mathrm{~m}^{-3}<\sigma_{3} \leq 41.46 \mathrm{~kg} \mathrm{~m}^{-3}$ and a deep layer between $41.46 \mathrm{~kg} \mathrm{~m}^{-3}$ and the seafloor (see Stöber, 2005, for details). Velocities are vertically averaged over each of the two density layers. For the complex demodulation only the three strongest tidal components of the area, the semidiurnal $M_{2}, S_{2}$, and $N_{2}$ frequencies, were taken into MAP.

Despite the limited amount of measurement points, the results of the demodulation compare well with the model predictions: The amplitude of the measured tidal currents of up to $5 \mathrm{~cm} \mathrm{~s}^{-1}$ agree within error bars with the model, except close to the seafloor, where topographic steering of the flow is dominant. The gross agreement of the measured velocities with the barotropic tidal model indicates that tidal flow is mainly barotropic throughout the most part of the rift valley. The increasing baroclinicity towards the seafloor is likely caused by the interaction between tidal flow and topography which generates tidal frequency internal waves not resolved by the time/space distribution of the stations used in the complex demodulation. 
The observed currents in north-south direction tend to exceed the model prediction, probably because of an amplification in along-valley direction. The overall agreement of the tidal phase between observations and model is remarkably good, thus a reliable determination of the tidal state for the individual profiles is feasible.

The tidal state is derived from the sea surface elevation of all partial tides supported by TPXO. Profiles recorded while the sea surface was lowering were categorized as ebb tide, profiles recorded during rising sea level as flood tide, respectively. For casts that included high or low water, the category was chosen depending on the predominant phase during the station time. For the tow-yo CTD stations and the ABE survey, duration and tidal phase with regard to high water are given individually in Tab. 1.

\subsection{Flow field and plume dispersal}

The currents close to the vent site are subject to strong modulation by the tides, as can be seen in the decomposition of the flow field into the motions at ebb and flood tide (Fig. 8): During ebb tide (falling sea level), the velocities are high, frequently more than $10 \mathrm{~cm} \mathrm{~s}^{-1}$, and the flow is circling around the topographic tip north of which the Drachenschlund is located (Fig. 8a,c). The direction is generally toward the southwest, with an average speed of $7 \mathrm{~cm} \mathrm{~s}^{-1}$ close to the vent site. Further away from the site, in the rift valley, the currents are weaker and less directional, although mainly with an along valley orientation, i.e. south-west/north-east. Below the non-buoyant plume layer, topographic blocking occurs, and the flow is more or less zero (Fig. 8c).

During flood flow (rising sea level), the average speed below the non- 
buoyant plume layer is close to zero, and no mean direction was observed below the non-buoyant plume layer in the whole area (Fig. 8d). Higher up in the water column, velocities close to the Drachenschlund are still minuscule, but stronger flow to the northeast occurs in the rift valley (Fig. 8b). The average of all measured currents close to the vent site over the two layers shown here, including ebb and flood, is directed to the southwest with a speed of $4 \mathrm{~cm} \mathrm{~s}^{-1}$. Above the plume layer (not shown), the flow is less restricted by the topography and generally to the north-east, with only minor tidal modulations.

Furthermore, there seems to be an impact of spring/neap cycles on the flow direction and hence the plume dispersal (Keir et al., 2008, not shown here): for two different weeks during the 2004 survey, there are some variations in direction as well as in speed of the flow variations which cannot solely be attributed to differences in location, since the positions of the stations are all within a few 100s of meters.

From the agreement between the tidal flow modulation in the direct current measurements and the observations of the particle plume in the water column (cf. Section 3), it can be concluded that the advection and dispersal of the plume varies strongly with tidal phase, which explains the observed high frequency variability in the plume signal.

\section{Turbulent Mixing}

\subsection{Overturn estimates of dissipation}

Vertical overturning is a result of turbulent motion and shows up as instability in measured density profile, where denser water is situated above 
lighter water. The turbulent dissipation rate $\varepsilon$ can be estimated from these density overturns by converting an observed density profile into one of stable stratification through resorting (Thorpe, 1977). Comparing the sorted and unsorted profiles shows vertical displacements of water parcels in turbulent patches. The mean displacement in an overturn is generally referred to as the Thorpe scale that is related to the dissipation rate in the patch.

To prevent the misinterpretation of instrument noise as overturns, different procedures have been proposed: One is the use of length of run, i.e. comparing the PDF of the run length of the displacements in a suspected overturn to that of white noise (e.g. Galbraith and Kelley, 1996; Stansfield et al., 2001); however, this method has been shown to be inconclusive (Johnson and Garrett, 2004). The more robust approach which is employed here is the determination of overturns from bin averaged CTD data (e.g. Ferron et al., 1998; Gargett and Garner, 2008); while this eliminates the possibility to identify the more abundant small displacements, the larger ones which dominate the Thorpe scale (Stansfield et al., 2001) are reliably detected.

The determination of displacements from preprocessed CTD data of 1 dbar resolution proposed by Ferron et al. (1998) has shown good agreement with direct microstructure measurements of dissipation rates. It requires a two step procedure to ensure sorting is not corrupted by instrument noise: Starting from an arbitrarily chosen reference value common for all profiles, two consecutive data points are considered significantly different if they differ by more than a value $\delta$, the threshold below which a signal is assumed to be smaller than the instruments noise. Thus, the sensitivity of the overturn detection is determined by the noise level of the measurements. If a small value 
for $\delta$ is chosen, noise may be mistaken for overturns; on the other hand, if a more conservative $\delta$ is assumed, some real overturns may be missed. Using this $\delta$, an intermediate profile is constructed, where the consecutive points differ by whole-number multiples of $\delta$. If the difference between two points in the original profile is smaller than $\delta$, they are considered the same, i.e. the vertical gradient vanishes in the intermediate profile.

While density is the physically relevant quantity when examining stability, there are two main drawbacks regarding the use of density profiles for the detection of overturns: Firstly, mismatched temperature and salinity sensors can cause spikes in the density profile, resulting in spurious overturns. Secondly, the relatively high noise level in density either leads to the interpretation of instrument noise as overturns, or compels the implementation of a vigorous noise rejection criterium, that obscures the signals of smaller overturns. The use of potential temperature instead of density profiles (as in Thorpe's original work) is an obvious remedy for both of these problems, since temperature has a better signal-to-noise ratio than density. However, applied in seawater, it requires a linear $\mathrm{T} / \mathrm{S}$ relation, as so not to interpret horizontal temperature intrusions, which are salinity compensated, as density inversions. The $\mathrm{T} / \mathrm{S}$ relationship in the region surveyed here is rather tight (Fig. 9a, cf. Fig. 3b) because of the limited horizontal and vertical extend of the area, thus it is warranted to use the temperature profiles for estimating dissipation rates.

The processing of the 1 dbar bin averaged potential temperature data to obtain Thorpe scales is implemented here closely following Ferron et al. (1998), and illustrated in Fig. 9: An intermediate temperature profile is 
constructed using a noise threshold of $\delta \mathrm{T}=0.001^{\circ} \mathrm{C}$ to avoid that instrument noise is wrongly interpreted as a real overturn. The noise threshold was chosen based on the inspection of quiet data during a slow instrument tow at a fixed depth $(\approx 2700 \mathrm{~m})$, which exhibited a noise level of $3 \times 10^{-4}{ }^{\circ} \mathrm{C}$, that corresponds to the instruments' resolution. The intermediate profile is then sorted (Fig. 9a); when temperature inversions are encountered, the displacement of a water parcel is given by the difference in depth in the unsorted and sorted profiles $T_{s}: d^{\prime}=z(T)-z\left(T_{s}\right)$. The Thorpe scale $L_{T}$ is the root-mean-square of all displacements within a turbulent patch, defined as a vertical interval within the displacements sum to zero (Fig. 9b).

Based on the relation between the Thorpe and the buoyancy length scale $L_{O}=\left(\varepsilon N^{3}\right)^{1 / 2}$, the instantaneous dissipation rate for a single patch is then

$$
\varepsilon_{i}=a^{2} L_{T}^{2} N^{3},
$$

where $N$ is the buoyancy frequency, calculated as $N^{2}=-\frac{g}{\rho} \frac{\partial \rho}{\partial z}$ using the sorted local potential density, which is subsequently averaged within the overturn (Fig. 9c). The coefficient $a$ is close to unity for oceanic environments (e.g. Dillon, 1982; Ferron et al., 1998). To get vertical profiles of the mean dissipation rate, all $\varepsilon_{i}$ are averaged into $50 \mathrm{~m}$ bins, with $\varepsilon_{i}$ set to zero where no overturn was detected (Fig. 9d). The turbulent diffusivity $K_{\rho}$ is then given by

$$
K_{\rho} \leq 0.2 \frac{\varepsilon}{N_{0}^{2}}
$$

(Osborn, 1980), where the buoyancy frequency $N_{0}$ is the average over all profiles for each depth bin.

For the computation of the profiles of dissipation and diffusivity, identical procedures have been applied to the tow-yo casts and to the regular CTD 
casts; this is legitimated by the fact that the physical aspect ratio of the towed casts is (due to the very low tow velocity of less than one knot) quite small: it ranges from less than 2:1 (780:450 m) for tow 1265, comprising five downcasts, to 6.5:1 (2930:450 m) for tow 103 with 11 downcasts. The resulting tilt of the instrument path is less than $15^{\circ}$ to the vertical and comparable to tilts in single-cast CTD profiles in the presence of typical ocean currents.

The results of the Thorpe scale analysis are sensitive to the choice of the noise threshold. A value too small would result into interpreting instrument noise as ocean turbulence, a too large threshold would suppress the detection of real overturns. Our value of $0.001^{\circ} \mathrm{C}$ was chosen conservatively, well above the instrument noise, which may result in loosing a number of smaller overturns; however, the resulting estimates of dissipation and diffusivity are dominated by the large number of huge overturns, and loosing smaller overturns may thus be acceptable. Using thresholds of $5 \times 10^{-4}{ }^{\circ} \mathrm{C}$ and $2 \times 10^{-3}{ }^{\circ} \mathrm{C}$ in the calculation did not show any qualitative changes in the results.

\subsection{Tidal cycle of diffusivity and dissipation}

\subsubsection{Axial valley}

Plume mapping during Meteor cruise 62/5 resulted in a substantial number of hydrographic stations located in the rift valley close to the Nibelungen field. This data (excluding the tow-yo casts) are used to estimate the strength of mixing in the valley. The stations, 33 in total, located roughly in a 10 by $10 \mathrm{~nm}$ square (Fig. 1c), are analyzed according to their temperature finestructure as described above. The results show remarkable difference between ebb and flood flow (Fig. 10). 
In the plume layer, the buoyancy frequency is fairly constant (about $0.5 \mathrm{cph}$ ), and the stratification exhibits virtually no tidal cycle (Fig. 10a). Above the plume, the stratification is stronger, and below, it decreases toward the seafloor. Despite the relatively constant $N$, there are large differences in the Thorpe scales between ebb and flood (Fig. 10b). In particular, the contrast is strong in the depth range between 2300 and $2800 \mathrm{~m}$, a nearly $500 \mathrm{~m}$ thick layer, that partially coincides with the upper part of the particle plume. Further differences between ebb and flood are found below $2900 \mathrm{~m}$, closer to the seafloor. In both cases, the Thorpe scales found during ebb are up to an order of magnitude larger than those observed during flood.

The resulting dissipation rates $\varepsilon$ fall between $10^{-10} \mathrm{~W} \mathrm{~kg}^{-1}$ and $10^{-9} \mathrm{~W} \mathrm{~kg}^{-1}$ for depths shallower than the upper edge of the nearby topography at $2300 \mathrm{~m}$ (Fig. 10c). Below $2300 \mathrm{~m}$, the flood $\varepsilon$ are up to more than an order of magnitude smaller than those during ebb flow in the same depths, and remain essentially at background level. During ebb, $\varepsilon$ increases to up to $10^{-8} \mathrm{~W} \mathrm{~kg}^{-1}$ in the upper edge of the plume, corresponding to the less structured horizontal currents during ebb (cf. Fig. 8a). In the lower part of the particle plume as well as close to the seafloor, the dissipation is smaller and the tidal differences become less developed.

The corresponding turbulent diffusivity shows a similar structure as the dissipation rate: During ebb flow, the turbulent diffusivity rises substantially below $2300 \mathrm{~m}$, with an average of $K_{\rho}=1.9 \times 10^{-3} \mathrm{~m}^{2} \mathrm{~s}^{-1}$ in the nonbuoyant plume layer, and maximum values of $K_{\rho}=6 \times 10^{-3} \mathrm{~m}^{2} \mathrm{~s}^{-1}$ found in the upper part of the plume layer. With a flood average of $K_{\rho}=6.8 \times$ $10^{-4} \mathrm{~m}^{2} \mathrm{~s}^{-1}$, the effective rift valley mean diffusivity in the effluent layer 
amounts to $K_{\rho}=1.9 \times 10^{-3} \mathrm{~m}^{2} \mathrm{~s}^{-1}$. The concurrence of the large variation in mixing strength with the proximity of the seafloor and the ridge crest convey a strong link between the current velocity and the mixing strength: The stronger and more variable currents during ebb tide (cf. Fig. 8) probably produce an enhanced level of internal wave activity and local mixing by interaction with the topography.

The most remarkable density inversion during flood tide was recorded on the downcast of station 1237, southwest of the Drachenschlund. Here, the instrument path intercepted the rising plume at a depth of approximately $2860 \mathrm{~m}$ (Fig. 11, and recorded positive temperature anomalies of close to $0.1^{\circ} \mathrm{C}$, which were accompanied by a large density inversion of more than $200 \mathrm{~m}$ thickness. Interestingly, the temperature anomaly is accompanied by a positive instead of a negative salinity anomaly. Although the higher salinity partly compensates the strong positive temperature anomaly, the stratification is still unstable, i.e. the density anomaly is negative. Instabilities associated to rising plumes were previously reported from the Juan de Fuca Ridge (Veirs et al., 1999); since they are not related to the background forcing, but directly caused by the rising plume, cast 1237 is excluded from the large scale estimate of ebb/flood background mixing shown in Fig. 10.

\subsubsection{Vent site}

The ebb-flood differences are also evident in the records from the towed CTD casts in close proximity to the vent site (Fig. 12). The average stratification is comparable to that in the rift valley, but the tidal modulation of the buoyancy frequency is stronger, especially in the deeper part below $2750 \mathrm{~m}$; here, the stratification is stronger during flood. The Thorpe scales 
are larger compared to the observations in the rift valley, particularly during ebb tide. The relative frequency of occurrence of overturns then is higher than during flood, and the probability of large overturns is higher (Fig. 13). Notably, there is a strong increase in $L_{T}$ at the top edge of the plume layer which is not evident in the flood records (Fig. 12)b). This increase is reflected in the coinciding rise of dissipation rates (Fig. 12)c) and turbulent diffusivities (Fig. 12)d) at the same depth. Both quantities are strongly elevated in the plume range and below during ebb tide, with maximum values of $\varepsilon>10^{-7} \mathrm{~W} \mathrm{~kg}^{-1}$ and $K_{\rho}>10^{-2} \mathrm{~m}^{2} \mathrm{~s}^{-1}$. During flood, there is no marked jump at the upper edge of the plume, and $\varepsilon$ and $K_{\rho}$ increase slowly towards their respective maxima in the center of the plume range at about $2800 \mathrm{~m}$ depth, where flood and ebb values attain similar magnitudes. Below these maxima, the divergence between ebb and flood increases again. The average turbulent diffusivity from all five tow-yo casts in the plume layer regardless of tidal state amounts to $K_{\rho}=4 \times 10^{-2} \mathrm{~m}^{2} \mathrm{~s}^{-1}$.

The occurrence of overturns is highly intermittent during the casts, and there is no direct link between presence of plume signals in a profile and the occurrence of overturns (Fig. 5, cf. Tab. 1), despite the sharp gradient in dissipation and diffusivity at the top of the plume layer. Large inversion during flood tide arose predominantly during cast 1265 (Fig. 5b), where the wave breaking may be an effect of the steep topography close to the track (cf. Fig. 1b).

\subsection{Internal waves}

All of the tow-yo casts showed considerable hydrographic variability on small temporal and spatial scales (Fig. 5). The large heave of the isothermals 
in the lower part of the plume points towards strong internal wave activity above the rugged topography. Internal waves are triggered by an interaction of tidal or mean currents with the underlying topography, and can cause vertical excursions of density surfaces of 10 s to 100s of meters. This is obviously the case here, where excursions of more than $100 \mathrm{~m}$ are observed. The breaking of internal waves causes turbulent mixing in the water column, and thus controls the erosion of a plume signal.

According to linear theory, internal waves must obey the dispersion relation

$$
\frac{N^{2}(z)-\omega^{2}}{\omega^{2}-f^{2}}=\left(\frac{\beta}{\alpha}\right)^{2}
$$

where $\alpha$ and $\beta$ are the horizontal and vertical wavenumbers, respectively. That is, the intrinsic frequency $\omega$ of propagating internal waves falls in the range between the local buoyancy frequency, $N$, and the Coriolis (or inertial) frequency, $f$, i.e. usually $f<\omega<N$. For our observations at Nibelungen, with $f\left(8^{\circ} 18^{\prime}\right)=2.1 \times 10^{-5} \mathrm{~s}^{-1}$, and $5 \times 10^{-4}<N<1.5 \times 10^{-3} \mathrm{~s}^{-1}$ (cf. Fig. 12), this corresponds to a range of possible wave periods between 1 and $83 \mathrm{~h}$. The average buoyancy frequency of around $N=8.5 \times 10^{-4} \mathrm{rad} \mathrm{s}^{-1}$ corresponds to an oscillation period of approximately $2 \mathrm{~h}$.

Assuming the individual profiles as stationary (an assumption justified by the small aspect ratio of the total casts, with less than $250 \mathrm{~m}$ horizontal distance between the individual measurement points at plume level, cf. Fig. 6), we observed undulations over a broad frequency range. Our time series are not sufficiently long to perform a spectral analysis of the periods involved; however, since these motions are partly coherent over vertical ranges of more than $100 \mathrm{~m}$, they are most likely an expression of internal waves. 
From visual inspection, the shortest periods in the record are of approximately $1 \mathrm{~h}$ period (e.g. the $2.4^{\circ} \mathrm{C}$ isotherm in Fig. $5 \mathrm{c}$ ), possibly indicative of waves trapped by topography. More common, especially during ebb flow, are periodic motions between 2 and $2.5 \mathrm{~h}$ with amplitudes ranging from a few 10s to $150 \mathrm{~m}$ (see e.g. the depth ranges between 2700 and $2900 \mathrm{~m}$ in Fig. 5a, or $2650-2800 \mathrm{~m}$ in Fig. 5e). These waves are close to the high frequency $(N)$ end of the internal wave spectrum, and therefore dissipated rapidly and locally, feeding their energy directly into mixing. Waves closer to the near-inertial subrange or in the tidal range have periods too long to be identified in our records. However, the high-frequency waves are superimposed on a background of sloping isotherms, which from this limited sample seem to be correlated with the tidal phase, and may be the signature of longperiod waves. For the three casts carried out during flood $(1257,1265$, \& 120, Fig. 5b,c,d), the general slope is (slightly) downward with time, while for the two tow-yos during ebb flow (1287 \& 103, Fig. 5a,e), the slope is orientated upward with time. This is probably owing to the changing flow pattern advecting different water bodies during the course of a tidal cycle.

The immediate local conversion of internal wave energy into mixing is reflected in the temperature finestructure and the observed overturns: The timeseries with the largest waves in the temperature record (1287, Fig. 5a), shows also the highest amount of finestructure variability in the temperature distribution, and the largest overturns. 


\section{Discussion}

\subsection{Strength of mixing}

Published estimates of turbulent mixing in rift valleys of mid-ocean ridges are sparse, with the notable exceptions of the Rainbow (Thurnherr et al., 2002; Thurnherr, 2006) and Lucky Strike (St. Laurent and Thurnherr, 2007) segments on the Mid-Atlantic Ridge of the North Atlantic. Here, large diapycnal diffusivities of up to $1.5 \times 10^{-2} \mathrm{~m}^{2} \mathrm{~s}^{-1}$ (Rainbow, Thurnherr et al., 2002) and $3 \times 10^{-2} \mathrm{~m}^{2} \mathrm{~s}^{-1}$ (Lucky Strike, St. Laurent and Thurnherr, 2007) were observed to occur in conjunction with flows over sills. The rift valley average for the Rainbow segment below $2000 \mathrm{~m}$ amounted to $K_{\rho} \approx 5 \times 10^{-3} \mathrm{~m}^{2} \mathrm{~s}^{-1}$ (Thurnherr et al., 2002). Half of this total was attributed to turbulence associated with hydraulically controlled flows over obstacles, and the other half to breaking of tidally forced internal waves (Thurnherr, 2006).

Additional comparable observations exist from fracture zones, which are of great importance to the deep ocean circulation: deep water is exchanged between oceanic basins, and, by diapycnal mixing, water mass properties are modified through buoyancy fluxes (e.g. Polzin et al., 1996). The observed diffusivities here are of a comparable magnitude, for example $K_{\rho}=10 \times$ $10^{-2} \mathrm{~m}^{2} \mathrm{~s}^{-1}$ in the Romanche Fracture Zone (southern MAR, Polzin et al., 1996; Ferron et al., 1998), or up to more than $K_{\rho}=10^{-2} \mathrm{~m}^{2} \mathrm{~s}^{-1}$ close to the seafloor in the Atlantis II Fracture Zone (Southwest Indian Ridge, MacKinnon et al., 2008). The larger scale averages in these fracture zones were found to be of $O\left(10^{-3} \mathrm{~m}^{2} \mathrm{~s}^{-1}\right)$. In general, rough topography at oceanic ridges leads to elevated mixing compared to the ocean interior, e.g. at the southern (Polzin et al., 1997), and northern (Mauritzen et al., 2002; Walter 
et al., 2005) MAR, or at the Hawaiian Ridge (Rudnick et al., 2003), all with similar $K_{\rho}$ up to $\times 10^{-3} \mathrm{~m}^{2} \mathrm{~s}^{-1}$.

The mixing strength observed on our surveys with $K_{\rho}$ around $10^{-3} \mathrm{~m}^{2} \mathrm{~s}^{-1}$ in the axial valley and around $10^{-2} \mathrm{~m}^{2} \mathrm{~s}^{-1}$ close to the vent site falls within the range of these previous observations. It is, however, notable and somewhat surprising that these relatively high diffusivities are found in a region with weak mean currents in the absence of jets and strong topographic controls: local Froude numbers $F r=\bar{U} /(\overline{N H})$ (where $\bar{U}, \bar{N}$, and $\bar{H}$ are the mean velocity, buoyancy frequency, and thickness of the plume layer, respectively, e.g. Whitehead, 1998), are subcritical in the axial valley and the vicinity of the vent site at Cheating Bay. Critical conditions where $\mathrm{Fr}$ approaches one (i.e. hydraulically controlled flow, which could lead to downstream mixing) are only observed very locally for the swift currents circling the topographic tip south of Cheating Bay; the only strong mixing events observed during flood tide (cast 1265, cf. Fig. 5b and 1b) may thus be a result of wave breaking downstream of a hydraulic jump.

The overall strong modulation of the mixing strength in our observations is a strong indication that the tides are the main energy source for mixing this particular segment of the Mid-Atlantic Ridge. In the absence of hydraulic control during ebb flow, the internal wave breaking results in strong overturns and mixing of comparable strength to that previously observed in conjunction with hydraulic jumps at sills and in fracture zones of mid-oceanic ridges.

\subsection{Internal wave generation}

Lots of high frequency internal waves close to the local buoyancy frequency have been observed. High frequency internal waves propagate in 
the vertical and are dissipated rapidly. Tidal waves are closer to the nearinertial range, and propagate in the horizontal, dissipating slowly. While the ebb/flood cycle observed in the far field of the vent site may be caused either by remote or local forcing of the internal waves responsible for the mixing, the high frequency waves observed at Cheating Bay imply a local generation, most likely by tide-topography interaction.

However, another possibility is the generation of high frequency waves by the (rising) plume itself: Internal waves of or close to buoyancy frequency in conjunction with a hydrothermal plume have been described by Lavelle (1997) in a numerical model, where the waves occurred downstream at or above the level of neutral buoyancy of the plume, and observed in the plume of the Kairei vent field (Central Indian Ridge) by Rudnicki and German (2002). Similar waves have been reported in the atmosphere in association with convective cells, both from models and observations (e.g. Clark et al., 1986; Hauf and Clark, 1989; Lane et al., 2001). Here, the generation of the waves was attributed to a nonlinear interaction between the thermal forcing of the convective plume and eddies in a (turbulent) layer below, with the actual mechanism of the wave formation unclear. A second possible mechanism for the excitation of high frequency waves by a rising plume is penetrative convection, which is also known from the atmosphere: it occurs when a plume overshoots from a well mixed layer into one of stable stratification, resulting in a train of gravity waves in the stratified layer (e.g. Stull, 1976). Depending on the stratification, large percentages of energy of the plume can be lost to local mixing. The internal waves at Kairei (Rudnicki and German, 2002) were, like those at Nibelungen, observed only during certain times of a tidal 
period, during which the stratification was rather weak. Thus, in eroding the stratification and stirring the near-boundary layer, tidal mixing my act as a preconditioning for further internal wave generation.

\subsection{Implications for plume dispersal}

The flow field and the mixing entail several consequences for the dispersal of the Drachenschlund plume. At the injection site of the fluids, the plume advection should be towards the southwest, following the ebb flow; this is hampered by the location of the Drachenschlund crater, which sits on the eastern side of a scarp (cf. Melchert et al., 2008), blocking the dominant direction of the current for the lowermost $80-90 \mathrm{~m}$ of the rising plume. In the range of the ascending and non-buoyant plume (2600 m - seafloor), the average flow speed throughout our observations was $7 \mathrm{~cm} \mathrm{~s}^{-1}$ during ebb tide, and $0 \mathrm{~cm} \mathrm{~s}^{-1}$ during flood tide, with a total average of $4 \mathrm{~cm} \mathrm{~s}^{-1}$. The peak velocities occurred during ebb tide and reached a maximum speed of around $20 \mathrm{~cm} \mathrm{~s}^{-1}$. The characteristic time scale of the rising plume to reach its equilibrium depth is $\tau \approx \pi N^{-1}$ (Middleton, 1986). With an average $N$ of $8.5 \times 10^{-4} \mathrm{~s}^{-1}$ in the area, the maximum rise time of the plume is approximately $1 \mathrm{~h}$, small compared to a tidal period. Thus, the advection of a signal to the point of observation must happen during one tidal period (ebb tide), with no further advection during flood tide. The repeated observation of a maximum plume signal about $600 \mathrm{~m}$ southwest of the vent implies a characteristic advection velocity of $16.5 \mathrm{~cm} \mathrm{~s}^{-1}$. Based on the measured velocity speed and direction, the maximum plume signal in the effluent layer should be found anywhere between $100 \mathrm{~m}$ (average advection) and $800 \mathrm{~m}$ (maximum advection) in the southwest region of the vent. This is supported 
by the plan-view ABE survey, which was potentially more systematic in terms of a horizontal snapshot of the plume core than the CTD tow-yos. The co-registered current velocity data showed the direction of flow at the time of sampling was, indeed, due West to South-West from Drachenschlund to the sites where the strongest backscatter signals were measured at nonbuoyant plume height (cf. Fig. 4). The observed distance between the vent site and the maximum turbidity signal is also indicative of currents larger than $10 \mathrm{~cm} \mathrm{~s}^{-1}$. When the particle plume has reached its equilibrium depth, it spreads to the southwest until it leaves the shallower region of Cheating Bay, where it is advected to the northeast by the along-valley flow.

\subsection{Plume bifurcation}

At the Rainbow vent site, German et al. (1998) speculated that the observed absence of the plume during some casts may be due to plume bifurcation caused by different rising heights during different tidal phases. Additionally, there is some observational evidence that turbulence can lead to plume bifurcation by the interplay between the turbulent overturns and the stratification (Ernst et al., 2000). This may indeed also be the case for the Drachenschlund plume: The factors governing the rise height of a plume are stratification, rotation, crossflow and strength of mixing (Middleton, 1986; Rudnicki et al., 1994; Lavelle, 1997; Rona et al., 2006). While, from our observations, the stratification close to the vent site seems not to be subject to large fluctuations with the tidal phase (cf. Fig. 12b), the turbulence and the strength of the crossflow on the other hand are. In his model, Lavelle (1997), found in fact that increased crossflow in the presence of mixing lead to stronger plume bending and eventual vertical bifurcation of the plume. 
The influence of rotation of the Drachenschlund plume should be negligible - the proximity of the Nibelungen site to the equator leads to a Rossby radius of the order of the width of the valley $(z N / f \approx 12 \mathrm{~km})$, so no additional focussing of the plume is expected. Interestingly, for such large ratios of $N / f$, laboratory experiments (Helfrich and Battisti, 1991) predict a vertical separation of the plume into two vortices of opposing rotational direction. Obviously no such large plume lenses have been observed or are even possible in the given setting, but possibly the underlying dynamics may play into the formation of the two plume layers with their different spreading directions.

\section{Summary and Conclusions}

Here, we investigated the consequences of turbulent mixing on the dispersal of a hydrothermal plume. Turbulent mixing rates were calculated from CTD profiles and tow-yo casts collected at the Nibelungen hydrothermal field in the South Atlantic.

The average turbulent diffusivity is essential for modeling the dispersal of the particle plume of a hydrothermal site, and its constituents. Keir et al. (2008) modeled the dispersal of the Drachenschlund plume with a Gaussian plume model, and found a vertical mixing rate $K_{v}$ between $9 \times 10^{-3} \mathrm{~m}^{2} \mathrm{~s}^{-1}$ and $8 \times 10^{-2} \mathrm{~m}^{2} \mathrm{~s}^{-1}$ necessary to produce the observed distribution of $\mathrm{CH}_{4}$ and $\delta^{3} \mathrm{He}$. Our estimates derived from the temperature finestructure analysis of the Cheating Bay tow-yos of $K_{\rho}=4 \times 10^{-2} \mathrm{~m}^{2} \mathrm{~s}^{-1}$ falls well within these brackets. The strength of the mixing follows a tidal cycle, with high turbulent diffusivities dominantly occurring during ebb flow, likely caused by the stronger currents interacting with the topography, and higher velocity shear. 
The magnitude of the observed mixing intensity is similar to observations at comparable locations on slow spreading ridges in the North Atlantic and Indian Ocean. In contrast to the fast spreading ridges in the Pacific, these are characterized by a steeper, more rugged bathymetry, favorable for an enhanced level of internal wave generation by interaction of currents with topography.

We find the tidally modulated strong mixing associated with rough topography at the Nibelungen site is consistent with several aspects of the plume dispersal: The rapid mixing results in a patchy plume with very short spatial scales and a high degree of short term variability. The interplay between the modulation in the mixing strength and current speed with the tides can result in a bifurcated plume, where the two cores spread in different directions. Internal waves of near-bouyancy frequency may be locally generated in the non-buoyant plume layer, possibly by nonlinear interaction between the buoyant plume and the elevated background turbulence or penetrative convection of the plume into the stratified layer above. These high frequency waves may be abundant in conjunction with slow spreading ridge sites, and add to plume dispersal by their local dissipation.

It is known that the dispersal of a hydrothermal plume that carries heat and chemical species into the ocean basins depends to a large extent on the topographic setting of the vent site. In general, the rapid dispersal of plumes by strong mixing, especially on slow spreading ridges, may have consequences for larger scale questions, e.g. the need for adapted surveying strategies considering a segment or basin wide census of hydrothermal systems in order to assess ridge spreading rates and the heat budget of the oceanic crust, which 
is, while not yet available, desirable for the South Atlantic.

\section{Acknowledgments}

We thank the officers and crews and fellow scientists of the Meteor during the cruises M62/5 and M68/1, and Alan Duester and Andrew Billings from the ABE team. Frank Zielinski took care of the MAPR during M62/5. Constructive comments and criticism from three anonymous reviewers helped to improve the manuscript. This work was supported by the Priority Program SPP1144 of the Deutsche Forschungsgemeinschaft; this is SPP 1144 contribution number 51. Funding for the ABE team from WHOI was provided by Grant \# OE-2006-218 from NOAA's Ocean Exploration Program; funding for the MAPR work was provided by NOAA's Vents Program.

\section{References}

Baker, E., and H. Milburn (1997), MAPR: A new instrument for hydrothermal plume mapping, Ridge Events, 8(1), 23-25.

Cannon, G., D. Pashinski, and M. Lemon (1991), Middepth flow near hydrothermal venting sites on the southern Juan de Fuca Ridge, J. Geophys. Res., 96, 12,815-12,831.

Clark, T., T. Hauf, and J. Kuettner (1986), Convectively forced internal gravity waves: Results from two-dimensional numerical experiments, Quart. J. R. Meteorol. Soc., 112(474), 899-925. 
Devey, C., K. Lackschewitz, and E. Baker (2005), Hydrothermal and volcanic activity found on the southern Mid-Atlantic Ridge, Eos Trans. AGU, 86(22), 209-216.

Dillon, T. (1982), Vertical overturns: A comparison of Thorpe and Ozmidov length scales, J. Geophys. Res., 87(C12), 9601-9613.

Egbert, G., and S. Erofeeva (2002), Efficient inverse modeling of barotropic ocean tides, J. Atmos. Oceanic Technol., pp. 183-204.

Ernst, G., R. Cave, C. German, M. Palmer, and R. Sparks (2000), Vertical and lateral splitting of a hydrothermal plume at Steinahóll, Reykjanes Ridge, Iceland, Earth Planet. Sci. Lett., 179, 529-537.

Ferron, B., H. Mercier, K. Speer, A. Gargett, and K. Polzin (1998), Mixing in the Romanche Fracture Zone, J. Phys. Oceanogr., 28(10), 1929-1944.

Galbraith, P., and Kelley, D. (1996), Identifying overturns in CTD profiles, J. Atmos. Oceanic Technol., 13, 688-702.

Garcia Berdeal, I., S. Hautala, L. Thomas, and H. Johnson (2006), Vertical structure of time-dependent currents in a mid-ocean ridge axial valley, Deep-Sea Res. I, 53, 367-386.

Gargett, A., and Garner, T. (2008), Determining Thorpe scales from shiplowered CTD density profiles, J. Atmos. Oceanic Technol., 25, 1657-1670.

German, C., K. Richards, M. Rudnicki, M. Lam, J. Charlou, and FLAME Scientific Party (1998), Topographic control of a dispersing hydrothermal plume, Earth Planet. Sci. Lett., 156, 267-273. 
German, C., D. Yoerger, M. Jakuba, T. Shank, C. Langmuir, and K. Nakamura (2008), Hydrothermal exploration with the Autonomous Benthic Explorer, Deep-Sea Res. I, 55, 203-219.

Hauf, T., and T. Clark (1989), Three-dimensional numerical experiments on convectively forced internal gravity waves, Quart. J. R. Meteorol. Soc., 115, 309-333.

Helfrich, K., and T. Battisti (1991), Experiments on baroclinic vortex shedding from hydrothermal plumes, J. Geophys. Res., $96(\mathrm{C} 7), 12,511-12,518$.

Jean-Baptiste, P., E. Fourré, A. Dapoigny, J. Charlou, and J.-P. Donval (2008), Deepwater mantle ${ }^{3}$ He plumes over the northern Mid-Atlantic Ridge $\left(36^{\circ} \mathrm{N}-40^{\circ} \mathrm{N}\right)$ and the Azores Platform, Geochem. Geophys. Geosyst., $9(3)$.

Johnson, H., and C. Garrett (2004), Effects of noise on Thorpe scales and run lengths, J. Phys. Oceanogr., 34(11), 2359-2372.

Keir, R., O. Schmale, M. Walter, J. Sültenfuss, R. Seifert, and M. Rhein (2008), Flux and dispersion of gases from the "Drachenschlund" hydrothermal vent at $8^{\circ} 18^{\prime} \mathrm{S}, 13^{\circ} 30^{\prime} \mathrm{W}$ on the Mid-Atlantic Ridge, Earth Planet. Sci. Lett., 270, 338-348.

Koschinsky, A., Billings, A., Devey, C., Dubilier, N., Duester, A., Edge, D., Garbe-Schnberg, D., German, C., Giere, O., Keir, R., Lackschewitz, K., Mai, H.A., Marbler, H., Mawick, J., Melchert, B., Mertens, C., Peters, M., Sander, S., Schmale, O., Schmidt, W., Seifert, R., Seiter, C., Stber, U., Suck, I., Walter, M., Weber, S., Yoerger, D., Zarrouk, M., Zielinski, F. 
(2006), Discovery of new hydrothermal vents on the southern Mid-Atlantic Ridge $\left(4^{\circ} \mathrm{S}-10^{\circ} \mathrm{S}\right)$ during cruise M68/1, InterRidge News, 15, 9-14.

Lane, T., M. Reeder, and T. Clark (2001), Numerical modeling of gravity wave generation by deep tropical convection, J. Atmos. Sci., 58, 12491274 .

Lavelle, J. (1997), Buoyancy-driven plumes in rotating, stratified cross flows: Plume dependence on rotation, turbulent mixing, and cross-flow strength, J. Geophys. Res., 102(C2), 3405-3420.

Lupton, J. (1995), Hydrothermal plumes: Near and far field, in Seafloor Hydrothermal Systems, Geophysical Monographs, vol. 91, edited by S. Humphries, R. Zierenberg, L. Mullineaux, and R. Thomson, American Geophysical Union, Washington, DC.

MacKinnon, J., T. Johnston, and R. Pinkel (2008), Strong transport and mixing of deep water through the Southwest Indian Ridge, Nat. Geosci., 1,755758 .

Mauritzen, C., K. Polzin, M. McCartney, R. Millard, and D. West-Mack (2002), Evidence in hydrography and density fine structure for enhanced vertical mixing over the Mid-Atlantic Ridge in the western Atlantic, $J$. Geophys. Res., 107(C10), 3147.

Melchert, B., et al. (2008), First evidence for high-temperature off-axis venting of deep crustal/mantle heat: the Nibelungen hydrothermal field, southern Mid-Atlantic Ridge, Earth Planet. Sci. Lett., 275(1-2), 6169. 
Middleton, J. (1986), The rise of forced plumes in a stably stratified crossflow, Boundary-Layer Meteorol., 36, 187-199.

Mihály, S., R. Thomson, and A. Rabinovich (1998), Evidence for nonlinear interaction between internal waves of inertial and semidiurnal frequency, Geophys. Res. Lett., 25(8), 1205-1208.

Osborn, T. (1980), Estimates of the local rate of vertical diffusion from dissipation measurements, J. Phys. Oceanogr., 10(1), 83-89.

Polzin, K., K. Speer, J. Toole, and R. Schmitt (1996), Intense mixing of Antarctic Bottom Water in the equatorial Atlantic Ocean, Nature, 380, $54-57$.

Polzin, K., J. Toole, J. Ledwell, and R. Schmitt (1997), Spatial variability of turbulent mixing in the abyssal ocean, Science, 276, 93-96.

Rona, P., K. Bemis, C. Jones, D. Jackson, K. Mitsuzawa, and D. Silver (2006), Entrainment and bending in a major hydrothermal plume, Main Endeavour Field, Juan de Fuca Ridge, Geophys. Res. Lett., 33, L19313.

Rudnick, D., Boyd, T.J., Brainard, R.E., Carter, G.S., Egbert, G.D., Gregg, M.C., Holloway, P.E., Klymak, J.M., Kunze, E., Lee, C.M., Levine, M.D., Luther, D.S., Martin, J.P., Merryfield, M.A., Moum, J.N., Nash, J.D., Pinkel, R., Rainville, L., Sanford, T.B. (2003), From tides to mixing along the Hawaiian Ridge, Science, 301, 355-357.

Rudnicki, M., and C. German (2002), Temporal variability of the hydrothermal plume above the Kairei vent field, $25^{\circ} \mathrm{S}$, Central Indian Ridge, Geochem. Geophys. Geosyst., 3(2), doi:10.1029/2001GC000240. 
Rudnicki, M., R. James, and H. Elderfield (1994), Near-field variability of the TAG non-buoyant plume, $26^{\circ} \mathrm{N}$, Mid-Atlantic Ridge, Earth Planet. Sci. Lett., 127, 1-10.

Rüth, C., R. Well, and W. Roether (2000), Primordial ${ }^{3}$ He in South Atlantic deep waters from sources on the Mid-Atlantic Ridge, Deep-Sea Res. I, 47, $1059-1075$.

Speer, K., and P. Rona (1989), A model of an Atlantic and Pacific hydrothermal plume, J. Geophys. Res., 94(C5), 6213-6220.

Speer, K., M. Maltrud, and A. Thurnherr (2003), A global view of dispersion above the mid-ocean ridge, in Energy and Mass Transfer an Marine Hydrothermal Systems, Dahlem Workshop Report, vol. 89, edited by P. Halbach, V. Tunnicliffe, and J. Hein, Dahlem University Press, Berlin.

Stansfield, K., C. Garrett, and R. Dewey (2001), The probability distribution of the Thorpe displacements within overturns in Juan de Fuca Strait, J. Phys. Oceanogr., 31(12), 4321-3434.

St. Laurent, L., and A. Thurnherr (2007), Intense mixing of lower thermocline water on the crest of the Mid-Atlantic Ridge, Nature, 448, 680683.

Stöber, U. (2005), Flow field and stratification at a hydrothermal vent site, Master thesis, Universität Bremen, Bremen http://iup.physik.uni-bremen.de/PEP_master_thesis/thesis_2005/Thesis_uwe.pdf

Stull, R.B. (1976), Internal gravity waves generated by penetrative convection, J. Atmos. Sci., 33, 1279-1286. 
Sültenfuss, J., M. Rhein, and W. Roether (2008), The Bremen Mass Spectrometric Facility for the measurement of helium isotopes, neon, and tritium in water, Isotopes Environ. Health Stud., 45(2), 1-13.

Thomson, R., S. Roth, and J. Dymond (1990), Near inertial motions over a mid-ocean ridge: Effects of topography and hydrothermal plumes, $J$. Geophys. Res., 95(C), 7261-7278.

Thomson, R., S. Mihály, A. Rabinovich, R. McDuff, S. Veirs, and F. Stahr (2003), Constrained circulation at Endeavour Ridge facilitates colonization by vent larvae, Nature, 424, 545-549.

Thorpe, S. (1977), Turbulence and mixing in a Scottish loch, Philos. Trans. R. Soc. London, A286, 125-181.

Thurnherr, A. (2006), Diapycnal mixing associated with an overflow in a deep submarine canyon, Deep-Sea Res. II, 53, 194-206.

Thurnherr, A., and K. Richards (2001), Hydrography and high-temperature heat flux of the Rainbow hydrothermal site $\left(36^{\circ} 14^{\prime} \mathrm{N}\right.$, Mid-Atlantic Ridge), J. Geophys. Res., 106(C5), 9411-9426.

Thurnherr, A., and K. Speer (2003), Boundary mixing and topographic blocking on the Mid-Atlantic Ridge in the South Atlantic, J. Phys. Oceanogr., 33(4), 848-862.

Thurnherr, A., K. Richards, C. German, G. Lane-Serff, and K. Speer (2002), Flow and mixing in the rift valley of the Mid-Atlantic Ridge, J. Phys. Oceanogr., 32(6), 1763-1778. 
844 Turner, J., and I. Campbell (1987), Temperature, density and buoyancy 845 fluxes in "black smoker" plumes, and the criterion for buoyancy reversal, 846 Earth Planet. Sci. Lett., 86, 85-92.

847 Veirs, S., R. McDuff, M. Lilley, and J. Delaney (1999), Locating hydrothermal 848 vents by detecting buoyant, advected plumes, J. Geophys. Res., 104(B12), $849 \quad 29,239-29,247$.

${ }_{850}$ Visbeck, M. (2002), Deep velocity profiling using Lowered Acoustic Doppler ${ }_{851}$ Profilers: Bottom track and inverse solutions, J. Atmos. Oceanic Technol., 852 $19(5), 794-807$.

853 Walter, M., C. Mertens, and M. Rhein (2005), Mixing estimates from a ${ }_{854}$ large-scale hydrographic survey in the North Atlantic, Geophys. Res. Lett., $855 \quad 32(13)$, L13605.

856 Whitehead, J. (1998), Topographic control of oceanic flows in deep passages 857 and straits, Rev. Geophys., 36(3), 423-440. 


\section{Tables}

Table 1: Summary of tidal phase of the CTD tow-yo casts and ABE survey. Given is date (dd/mm/yy), start time of the cast (UTC), tidal phase at start in hours relative to high water $(\mathrm{HT})$, tidal phase with $\nearrow(\searrow)$ indicating rising (falling) tide, and the duration of the cast in hours.

\begin{tabular}{llrlcc}
\hline Cruise & Station & Date & StartTime/Phase & Tide & Duration \\
\hline \hline M62/5 & CTD 1257 & 10/12/04 & 10:19 UTC, HT-5.6h & $\nearrow$ & $2.7 \mathrm{~h}$ \\
& CTD 1265 & $11 / 12 / 04$ & $22: 36$ UTC, HT-5.2 h & $\nearrow$ & $1.5 \mathrm{~h}$ \\
& CTD 1287 & $17 / 12 / 04$ & $11: 26$ UTC, HT+2.2 h & $\searrow$ & $2.9 \mathrm{~h}$ \\
M68/1 & CTD 103 & $22 / 05 / 06$ & $15: 05$ UTC, HT+2.1 h & $\searrow$ & $3.2 \mathrm{~h}$ \\
& CTD 120 & $26 / 05 / 06$ & $11: 02$ UTC, HT-5.5 h & $\nearrow$ & $2.9 \mathrm{~h}$ \\
& ABE 177 & $20 / 05 / 06$ & $20: 03$ UTC, HT-4.5h & $\nearrow$ & $10.8 \mathrm{~h}$ \\
\hline
\end{tabular}


${ }_{859}$ Figure Captions 

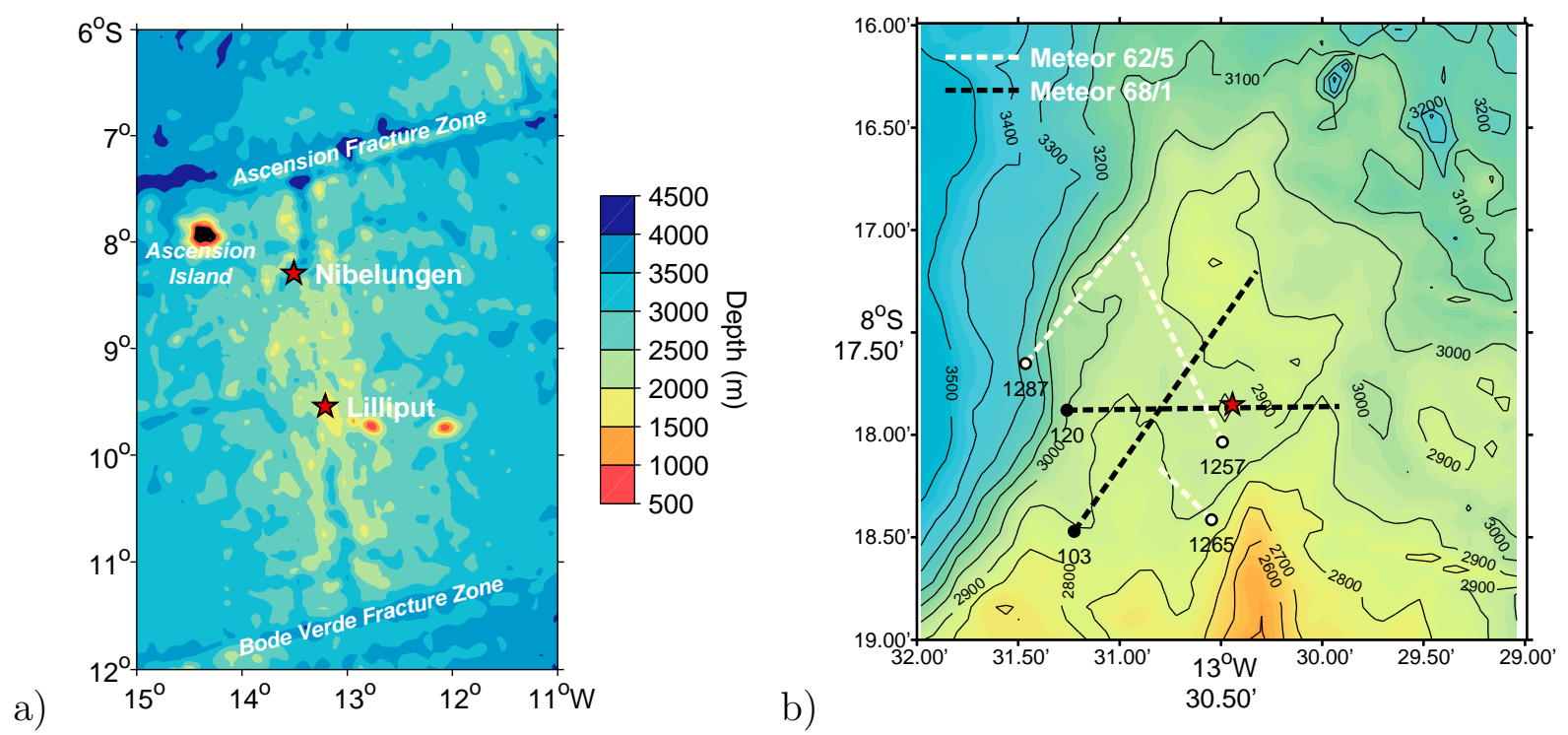

b)

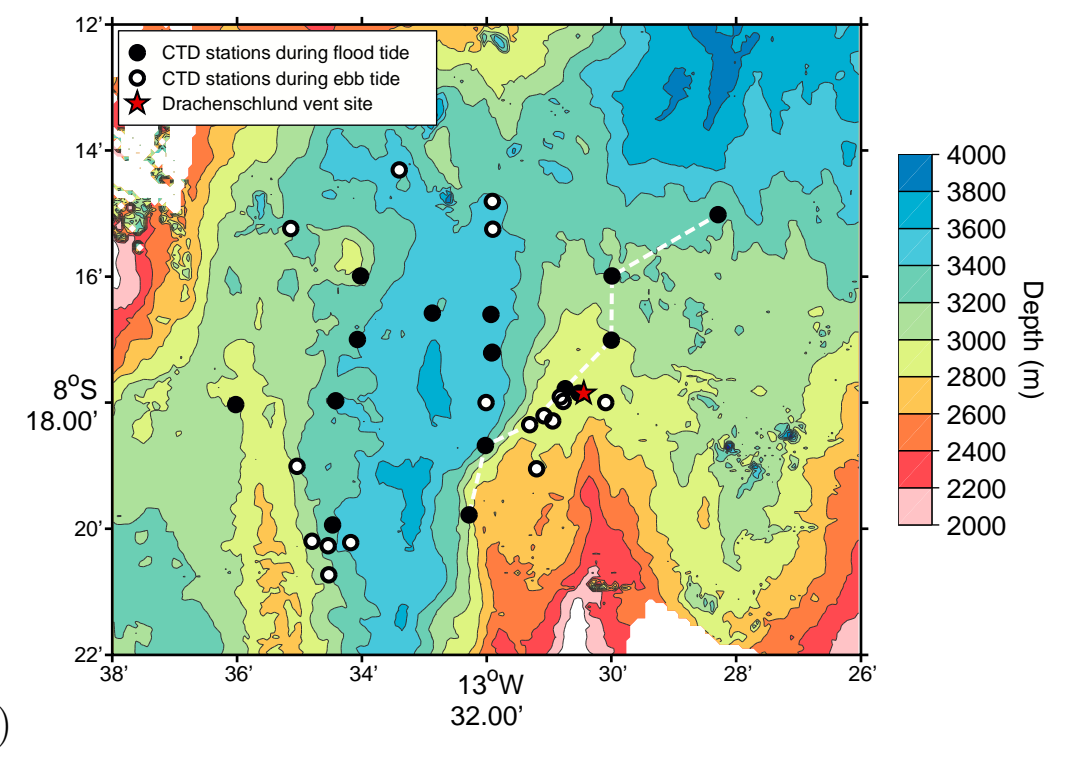

Figure 1: a) Overview of the South Atlantic with the location of the Nibelungen field; also marked is the low-temperature field Lilliput south of Nibelungen. b) Cheating Bay with the tow-yo shiptracks during Meteor cruises M62/5 (Dec. 2004) and M68/1 (May 2006); the towed instrument is typically 300 to $500 \mathrm{~m}$ behind the ship. Starting points are indicated by dots, the Drachenschlund vent is marked by the red asterisks. c) M62/5 non-towed CTD stations with color-coded tidal state (black: flood, white: ebb) in the vicinity of Nibelungen; the white dashed line denotes the location of the section shown in Fig. 7. Stations farther away from the Nibelungen field are omitted (see Keir et al., 2008, for a complete listing). Bathymetry in (b) and (c) was collected during M62/5 (Atlas/HYDROSWEEP DS/, 15.5 kHz multibeam echosounder) and M68/1 (Kongsberg/EM 120/, 12 kHz multibeam echosounder). 


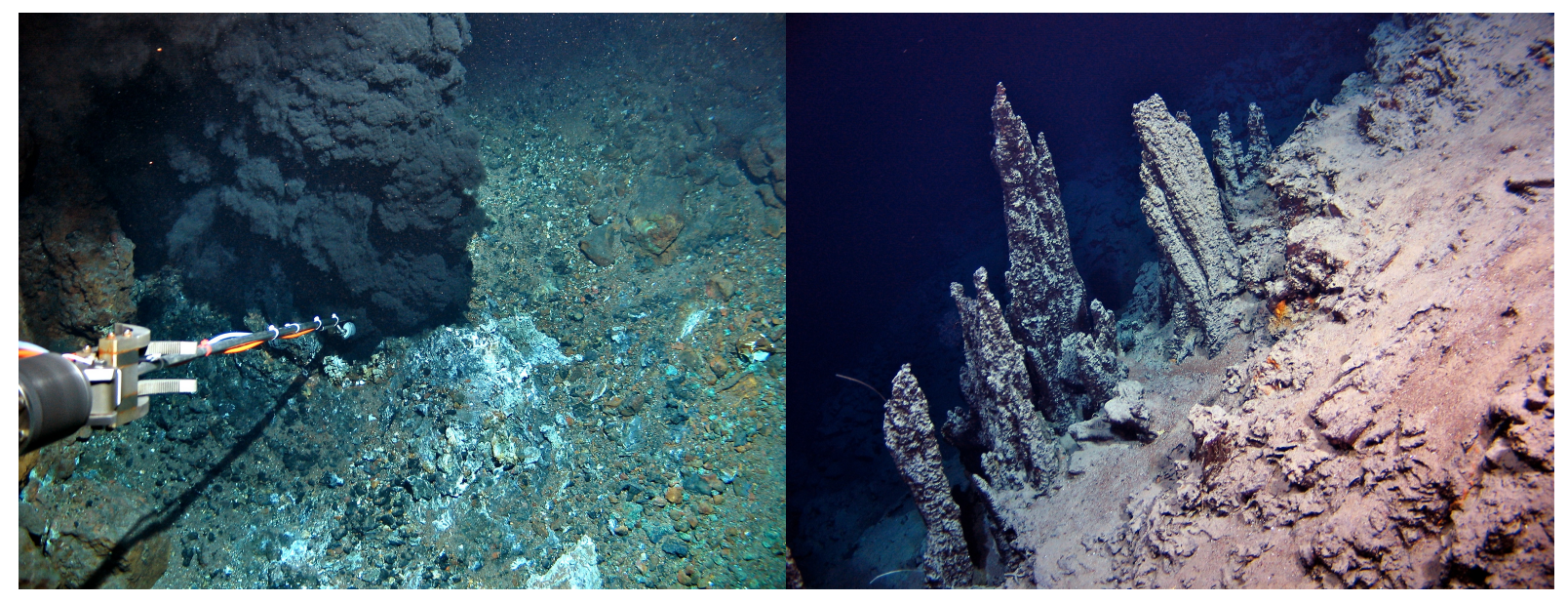

Figure 2: The Nibelungen hydrothermal field: Temperature measurements at smoking crater Drachenschlund (left), and extinct structures (right). (Photos taken during Meteor cruise M78/2, April 2009; (CIfM-GEOMAR, Univ. Kiel.) 

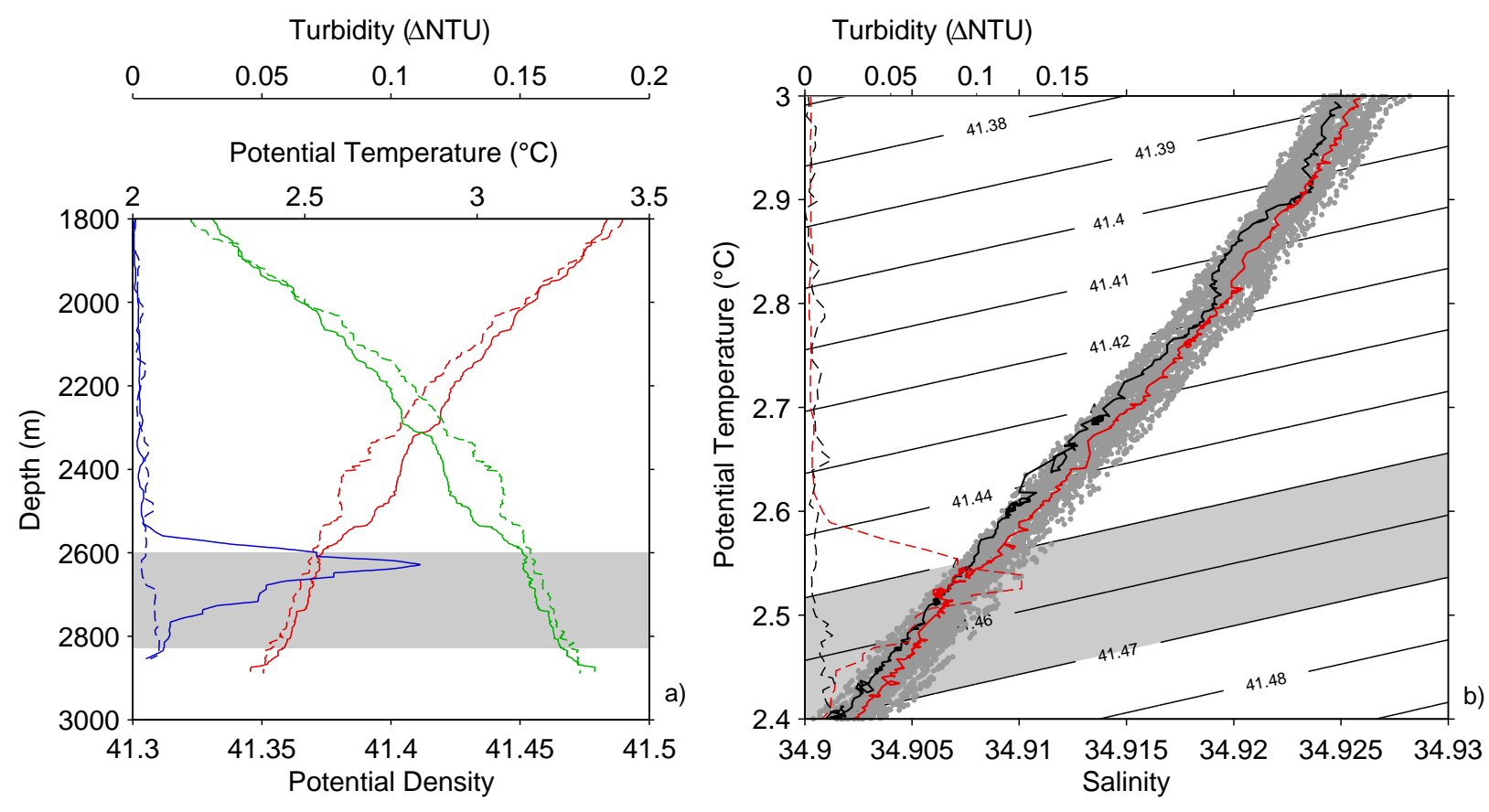

Figure 3: a) Profiles of potential temperature (red), potential density relative to 3000 dbar (green), and turbidity (blue) from the cast with the strongest plume signal during Meteor $62 / 5$ (station 1230, solid lines) and a repeat cast at the same position, but 10 days later (station 1276, dashed lines). b) Temperature/salinity diagram of the same two casts (solid lines, red: 1230; black: 1276). Additionally shown for comparison is the turbidity signal versus temperature (dashed lines), and the scatter of all CTD casts in the vicinity of Cheating Bay (dark grey). The depth/density range of the plume is shaded in light grey in both panels. 


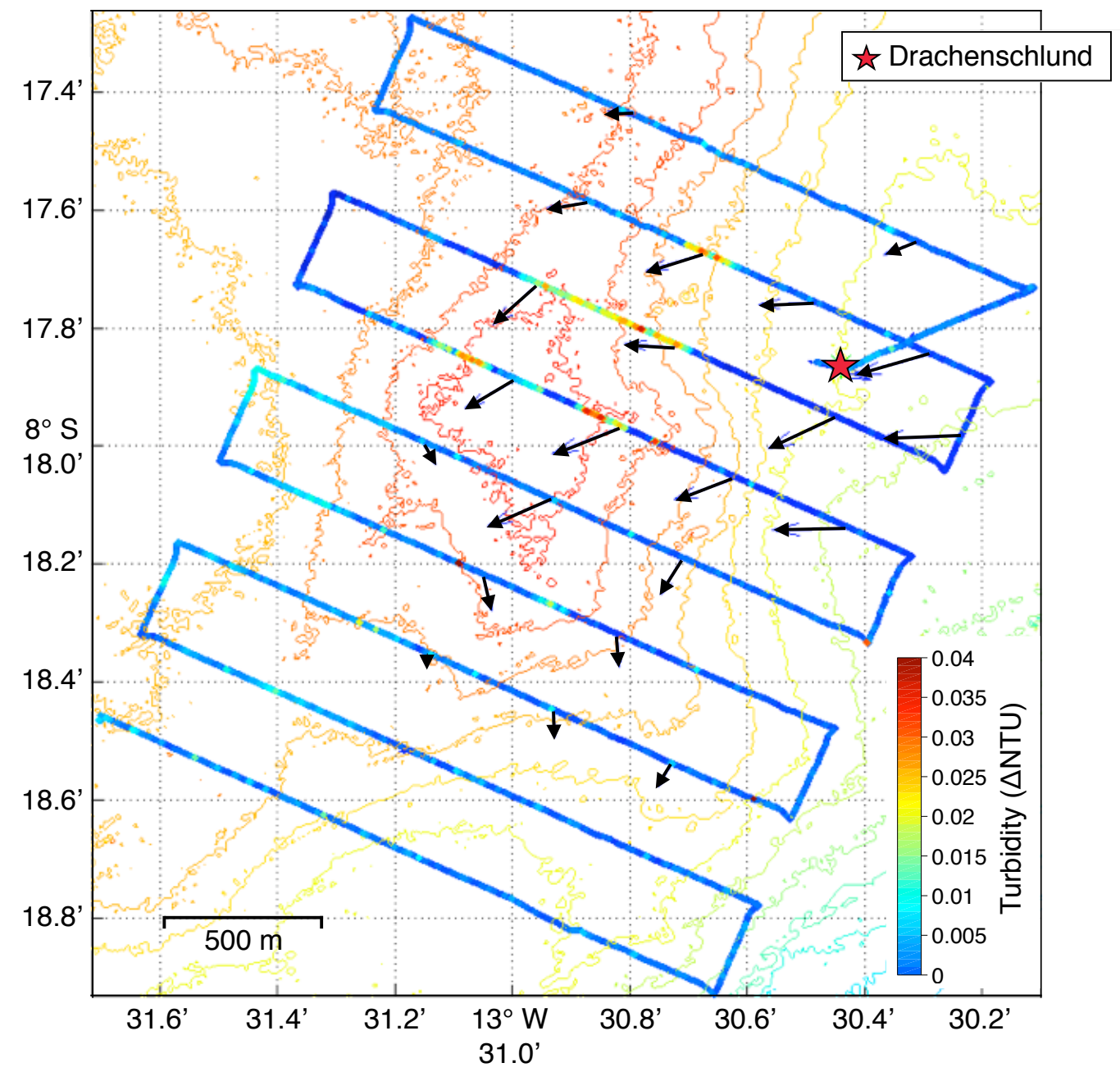

Figure 4: AUV ABE alongtrack turbidity from optical backscatter sensor and current direction and magnitude as estimated from the bottom and water lock velocities at the non-buoyant plume level $(2700 \mathrm{~m})$. Data from ABE Dive 177, Phase 1 at Nibelungen (May 2006). The survey is centered at the depth of the previously located plume signal, line spacing is approximately $300 \mathrm{~m}$. Underlying contours indicate bathymetry. 

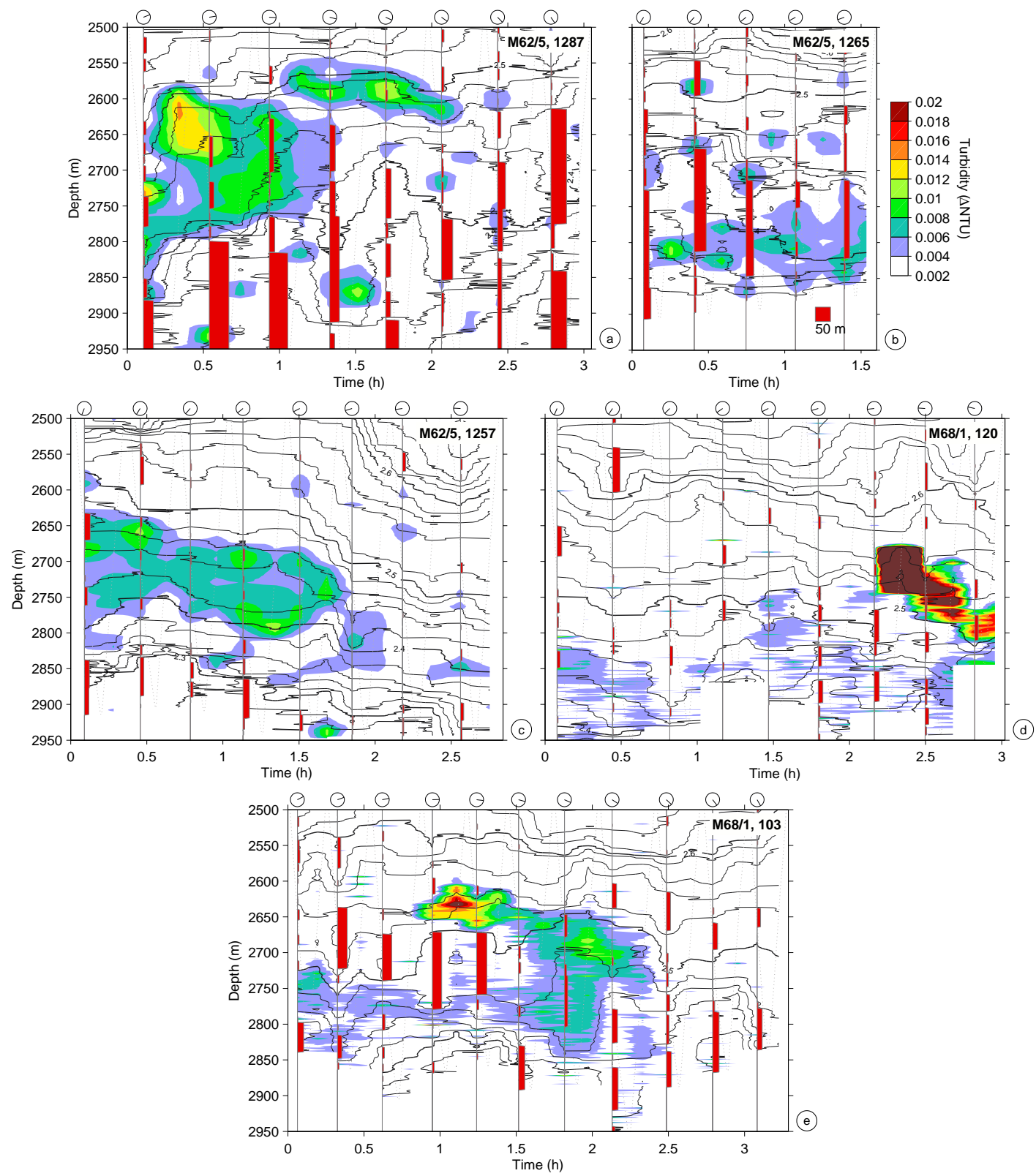

Figure 5: Towed time series of turbidity (CTD/MAPR) and potential temperature in the vicinity of the vent site (tracks are shown in Fig. 1b). Filled contours denote the turbidity, black lines isothermals. The path of the instrument package is indicated by the light grey line. Red rectangles mark the Thorpe scales $L_{T}$ and the vertical extent of the turbulent patches during the downcasts (see Section 5 for details). Colorbar and $L_{T}$ scale in panel b) apply for all panels. Tidal phase is indte 4 ted on top of each profile, with 12 o'clock indicating high tide and 6 o'clock low tide, respectively. 


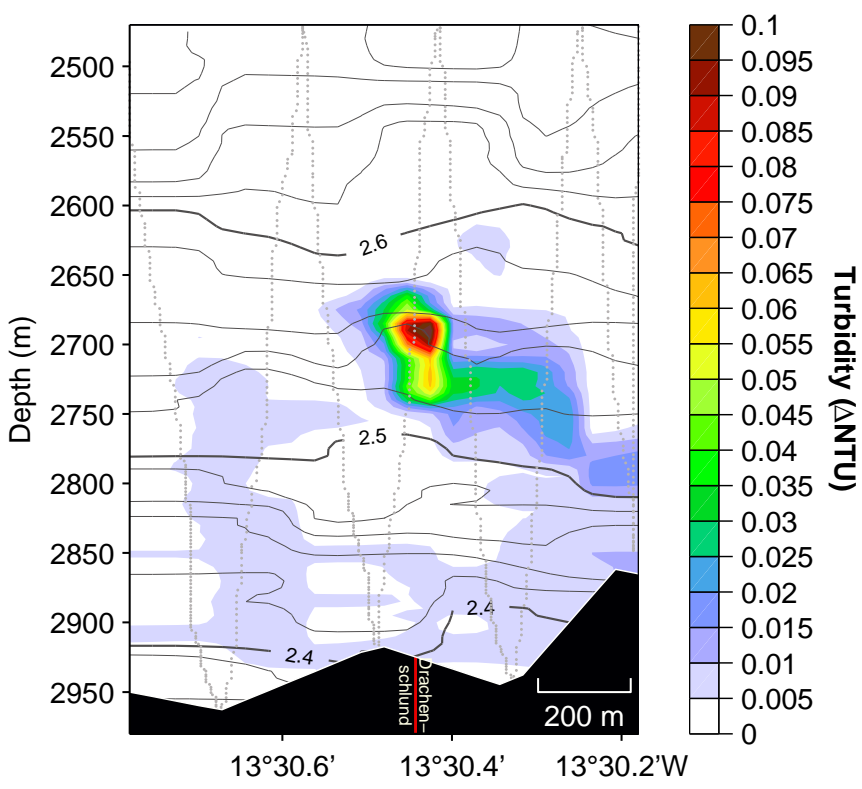

Figure 6: Transect of turbidity versus longitude directly across the location of the Drachenschlund vent (M68/1, Stn. 120; cf. Fig. 1b). Contoured is a composite of smoothed data from the CTD backscatter sensor and three MAPRs (100, 150 and $200 \mathrm{~m}$ above the CTD); isothermals are shown as dark grey contours. The grey dotted line denotes the path of the towed instruments; the track was from the SW (left) to the NE (right), with high tide shortly before the begin of the tow, thus the tow was against the ebb tide flow. 


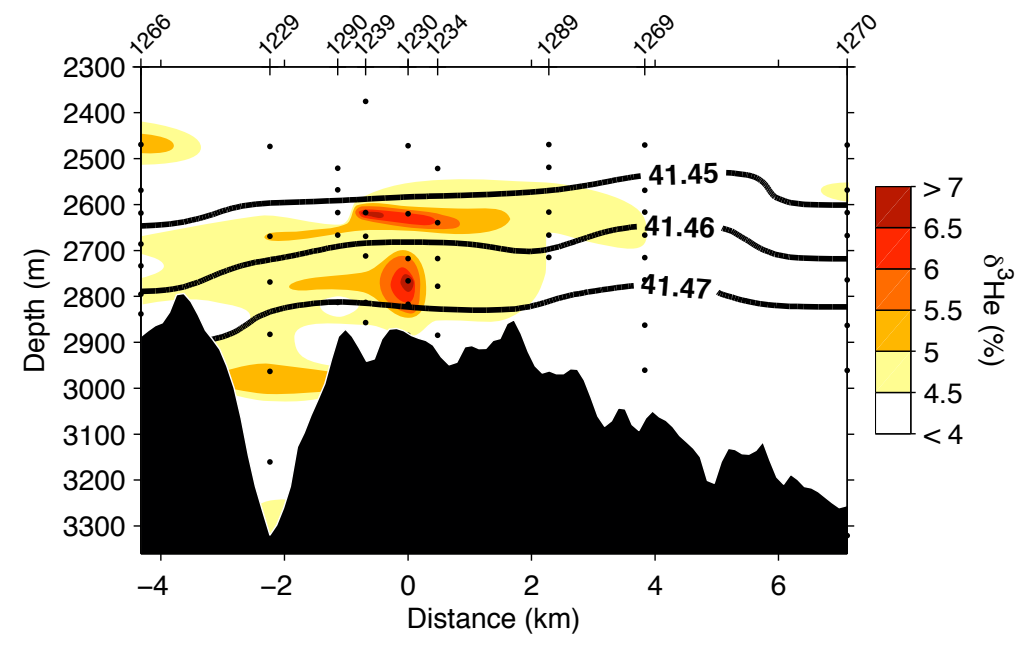

Figure 7: Interpolated $\delta^{3} \mathrm{He}$ (relative difference of ${ }^{3} \mathrm{He} /{ }^{4} \mathrm{He}$ ratio from atmospheric air in \%) transect across Cheating Bay (SW to NE, cast 1234 is closest to the Drachenschlund; see Fig. 1c for position); data points are indicated by the black dots. Also shown are the isopycnals $\sigma_{3}=41.45,41.46$, and $41.47 \mathrm{~kg} \mathrm{~m}^{-3}$, which confine the plume in the vertical. 

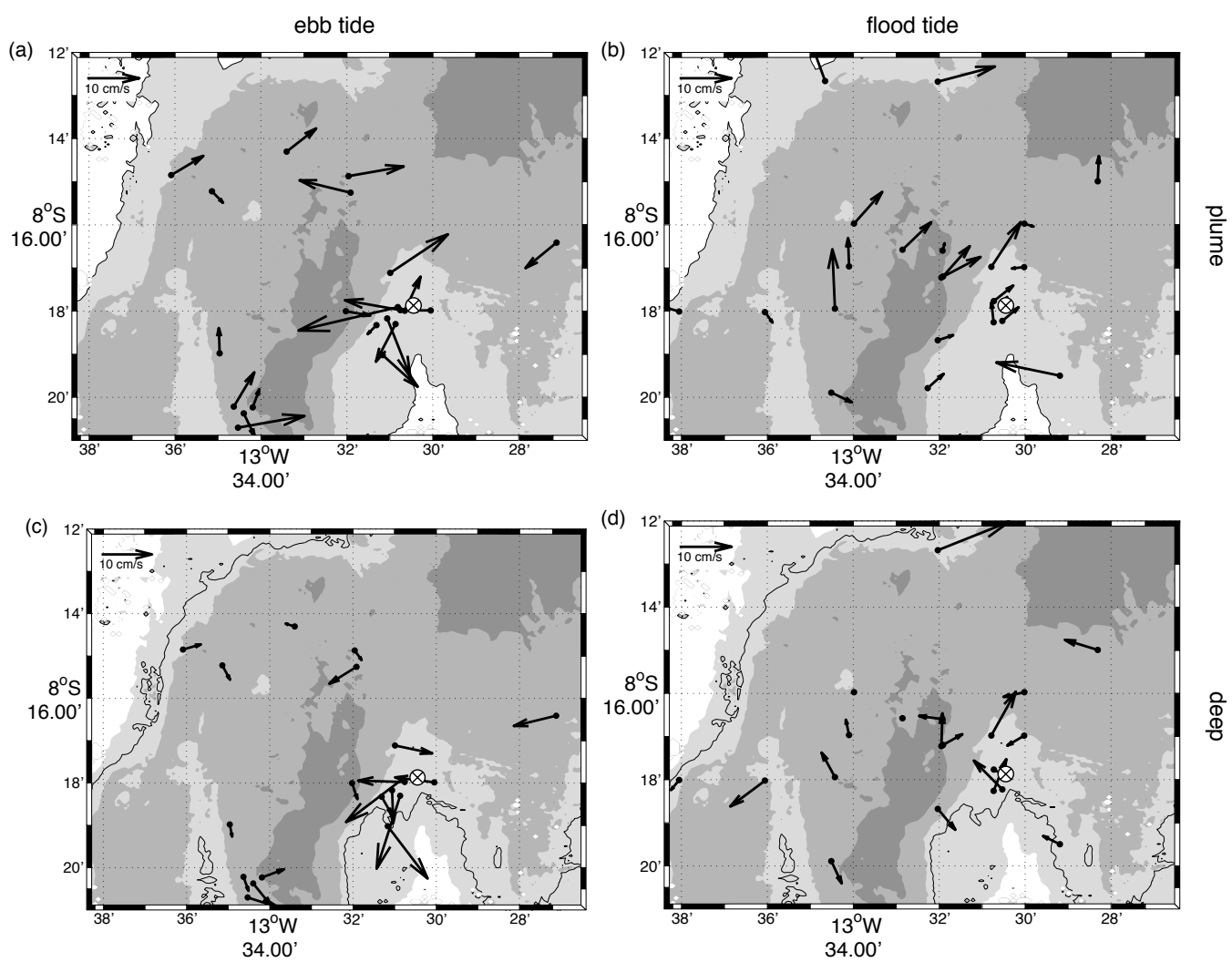

Figure 8: Direct current measurements (black arrows) during different tidal phases (a,c: ebb tide; b,d: flood tide). Solid bathymetric contours denote the shallowest isobaths limiting the plume dispersal in the respective density ranges. (a,b) Average velocities for the non-buoyant plume density range $\left(41.44<\sigma_{3} \leq 41.46\right)$; the shallowest isobath in this density range is $2500 \mathrm{~m}$. (c,d) Average velocities between non-buoyant plume and seafloor $\left(\sigma_{3}>41.46\right)$; the shallowest isobath in this density range is $2800 \mathrm{~m}$. Underlying bathymetry is shown in greyscale with $500 \mathrm{~m}$ intervals, the position of the Drachenschlund is marked by the crossed out white circle. 

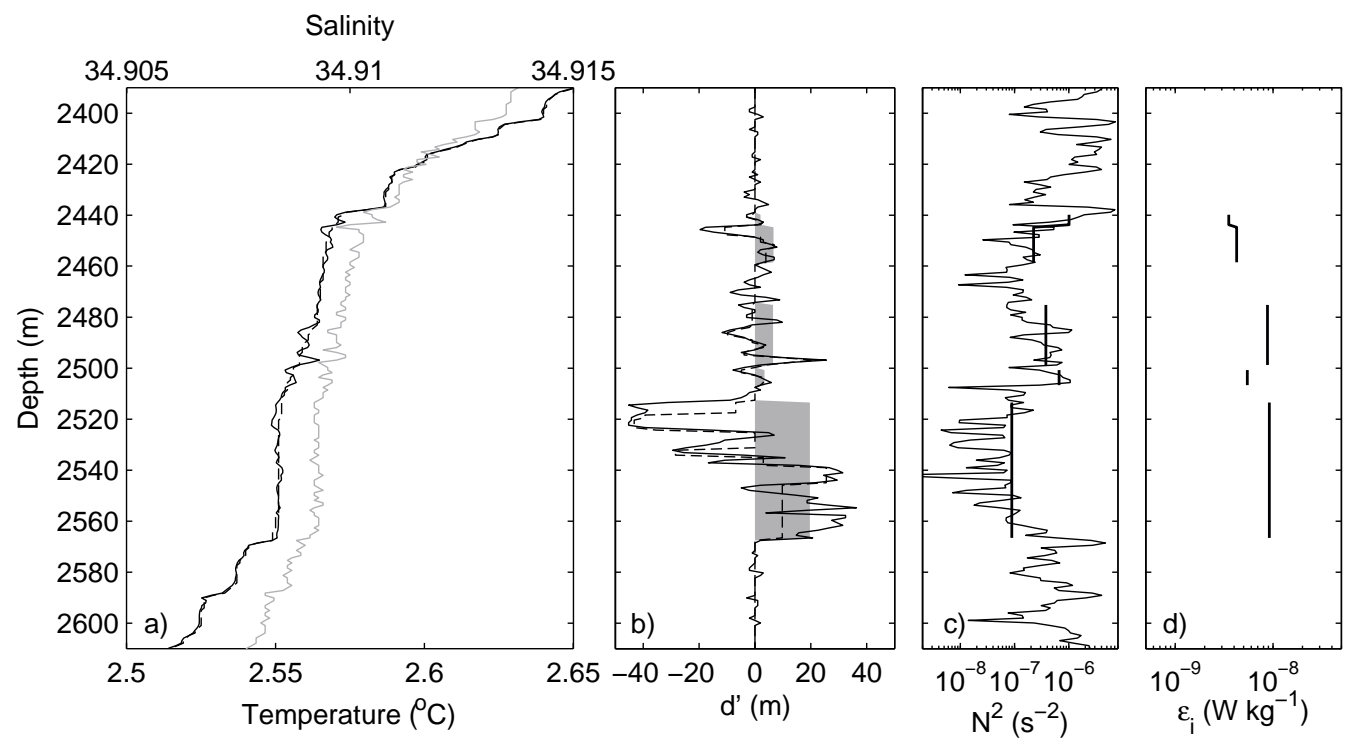

Figure 9: Example (Meteor 62/5, cast 1214) of the calculation of dissipation rate from temperature profiles using Thorpe scales. a) 1 dbar temperature (black), and salinity (grey) profile. Also shown (dashed) is the intermediate (sorted) temperature profile following the method described by Ferron et al. (1998). b) Thorpe displacements $d^{\prime}$, calculated from the original (solid) and intermediate (dashed) profile. Vertical extend of inversions and corresponding Thorpe scale is indicated by the grey rectangles. c) Buoyancy frequency $N^{2}$; vertical lines denote the average $N^{2}$ for the patches marked in (b). d) Resulting instantaneous dissipation rate $\varepsilon_{i}$ for each patch. 

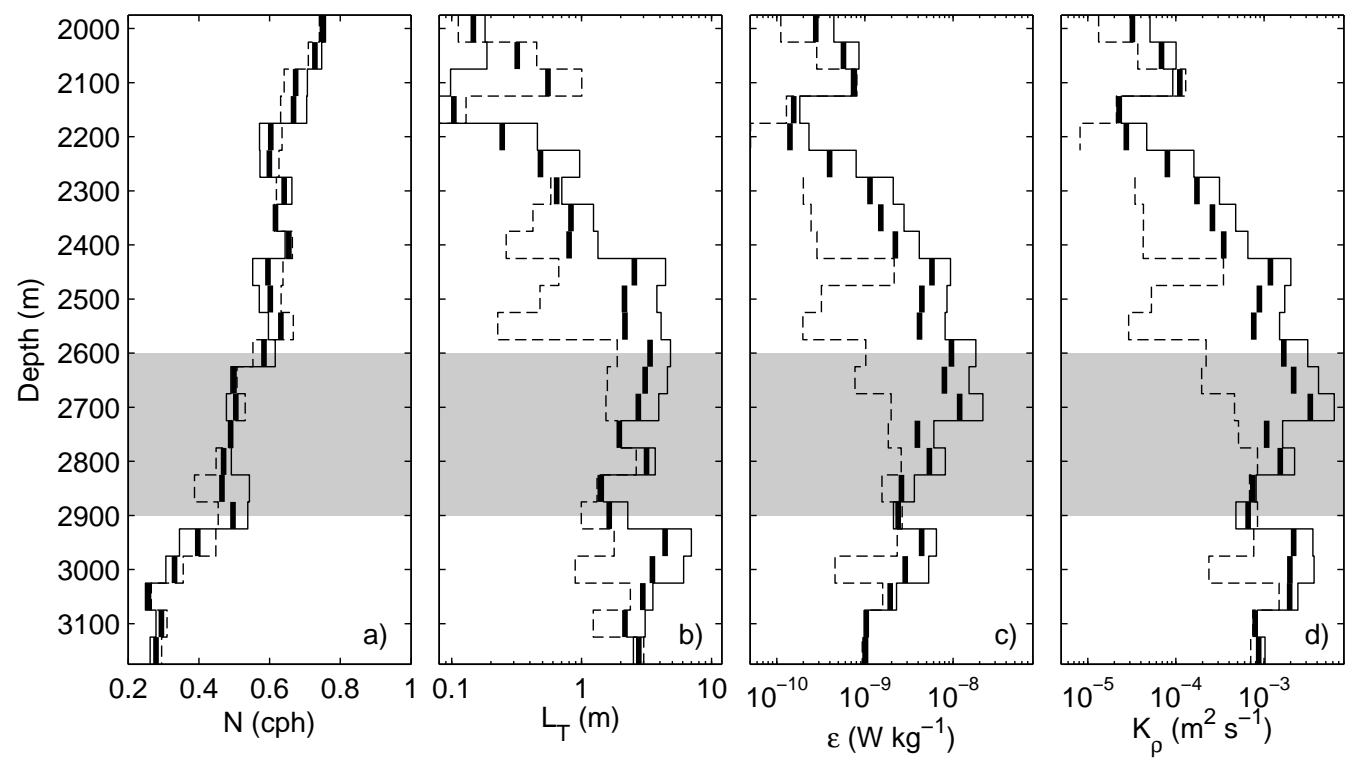

Figure 10: Stratification (a), average Thorpe scale (b), average dissipation rate (c), and turbulent diffusivity (d) for all CTD casts in the vicinity of Nibelungen (solid bold), during flood (thin dashed, 16 profiles) and ebb (thin solid, 17 profiles) flow. The depth range of the plume is shaded in grey. 


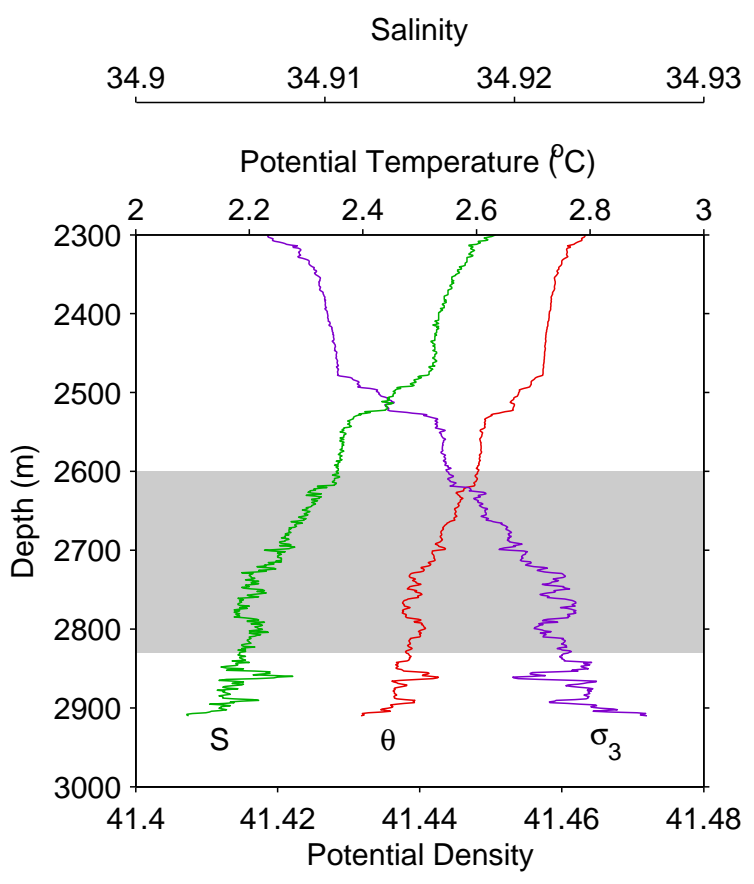

Figure 11: Rising plume profile (Meteor 62/5,1237); profiles of potential temperature (red), potential density relative to $3000 \mathrm{dbar}$ (green), salinity (purple), and Thorpe displacements (black); non-buoyant plume range is shaded in grey. 

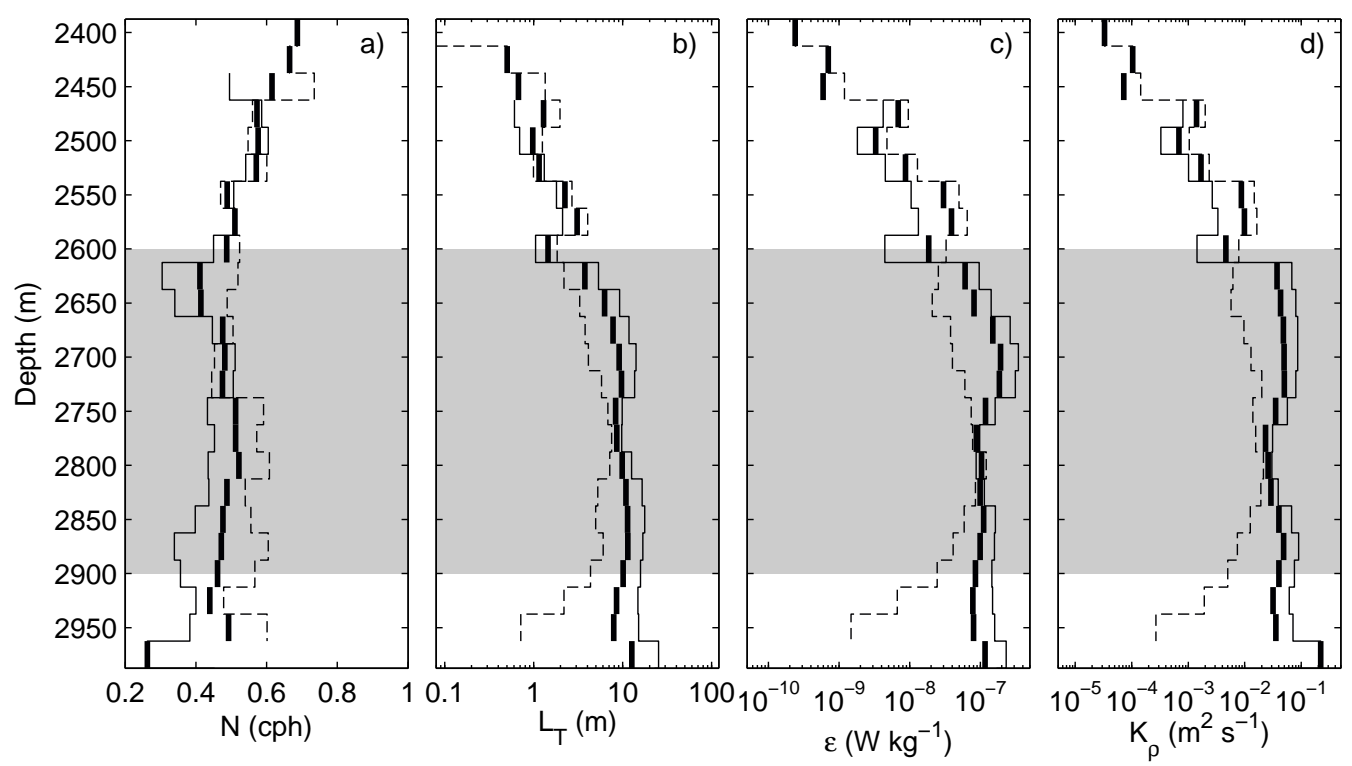

Figure 12: Stratification (a), average Thorpe scale (b), average dissipation rate (c), and turbulent diffusivity (d) for the near-field tow-yo casts (cf. Fig. 5, for location/tracks see Fig. 1b). The bold black line is the average over all cast, thin dashed and thin solid denote flood and ebb flow only, respectively. The depth range of the plume is shaded in grey. 


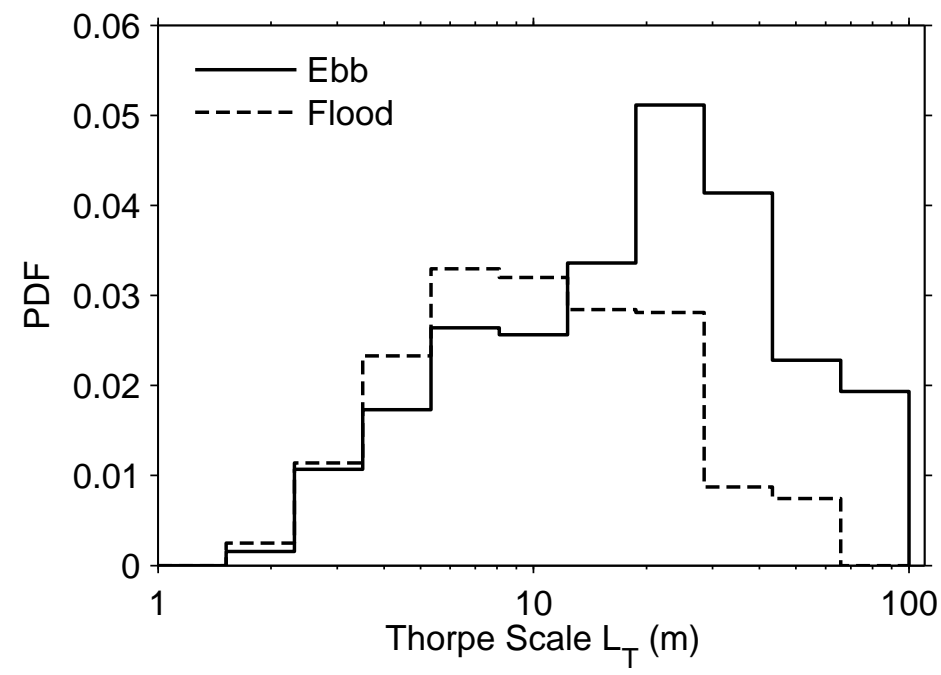

Figure 13: Distribution of Thorpe scales $L_{T}$ during ebb (solid) and flood (dashed) tide, calculated from temperature inversions during the tow-yo casts at the Nibelungen site (Fig. 1b). 